\title{
N/Sก
}

\section{CHARACTERIZATION OF ADVANCED ELECTRIC PROPULSION SYSTEMS}

\author{
PREPARED FOR \\ LEWIS RESEARCH CENTER \\ NATIONAL AERONAUTICS AND SPACE ADMINISTRATION \\ GRANT NAG 3-76
}

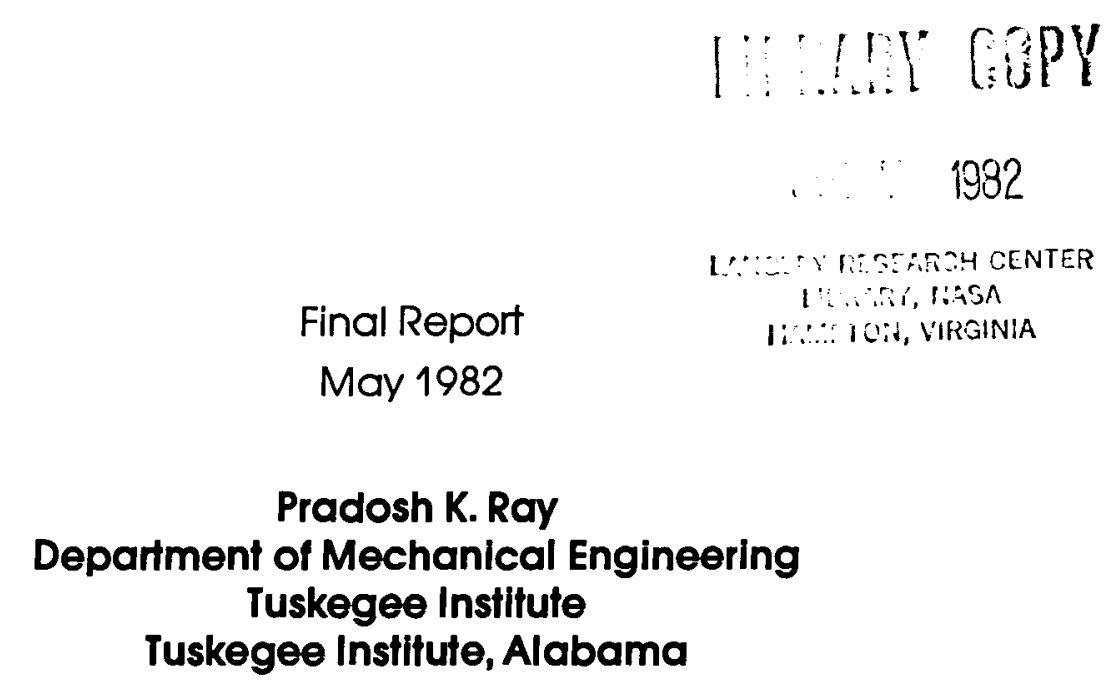




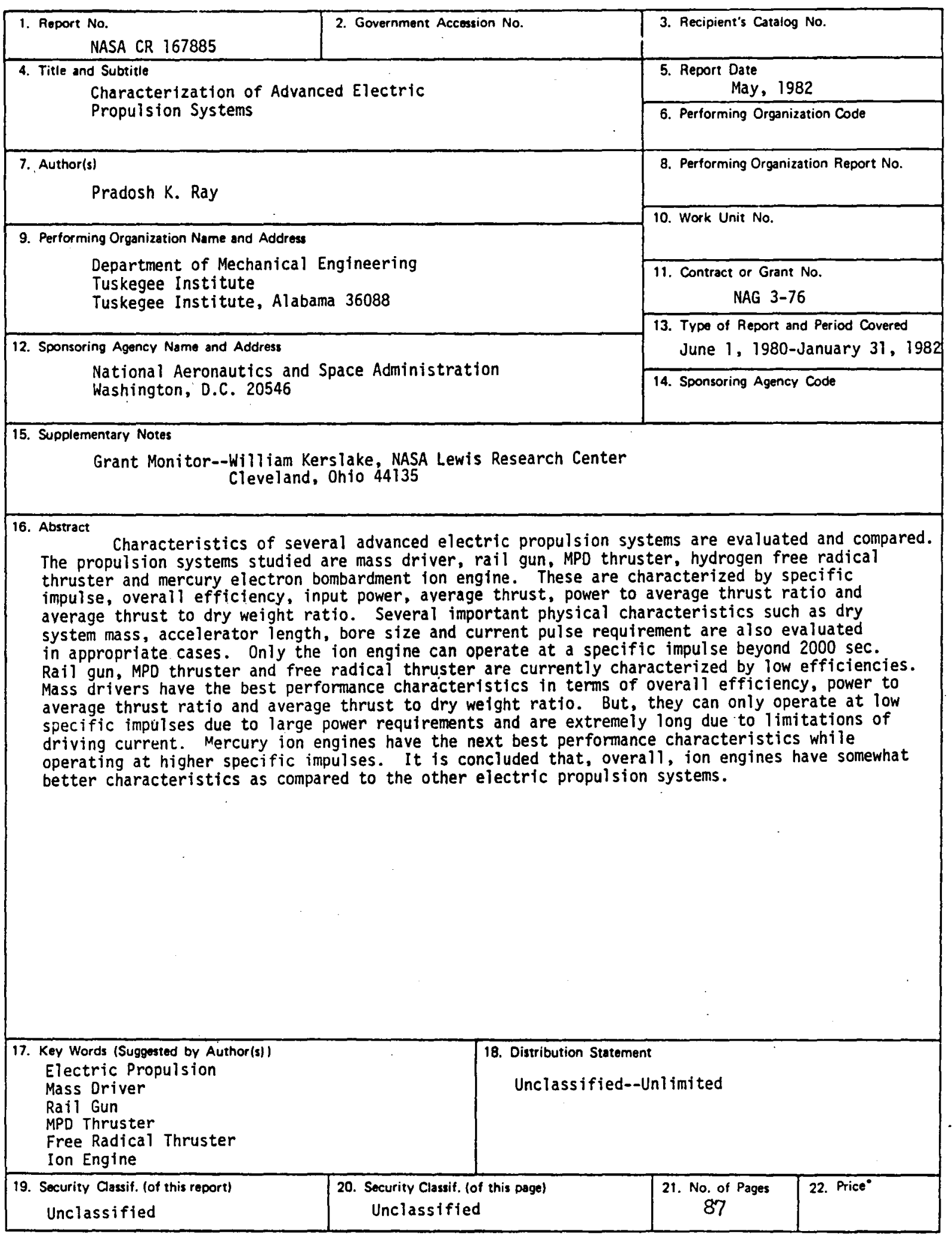

* For sale by the National Technical Information Service, Springfield. Virginia 22161 
This Page Intentionally Left Blank 
$\underline{\text { Topic }}$

Page

Abstract ..........................

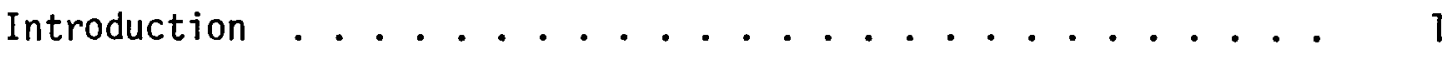

Electric Propulsion Systems .............. 3

System Description .................... 6

Mass Driver ....................... 6

Rail Gun Thruster .................... 8

MPD Thruster ................ . . 8

Free Radical Thruster . . . . . . . . . . . . . 10

Mercury Electron Bombardment Ion Thruster . . . . . 12

Results...................... 15

Mass Driver ................ . . . 15

Rail Gun Thruster ............... 23

MPD Thruster .................. 35

Free Radical Thruster . . . . . . . . . . . . 35

Mercury Electron Bombardment Ion Engine ........ 40

Comparative Evaluation ............. 52

Conclusions ........................... 60

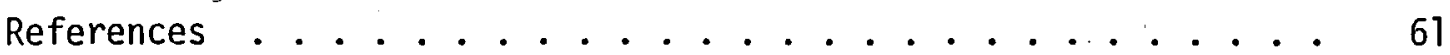

Appendix A--Axial Mass Driver.............. 64

Appendix B--Rail Gun Thruster............. 68

Appendix C--MPD Thruster ................ 71

Appendix D--Free Radical Thruster. . . . . . . . . 73

Appendix E--Mercury Electron Bombardment Ion Thruster . . . . . 76

Distribution List . . . . . . . . . . . . . 77 
This Page Intentionally Left Blank 


\section{LIST OF FIGURES}

Figure No.

$\underline{\text { Title }}$

Page

1. Schematic Diagram of a Mass Driver Reaction Engine . . 7

2. Schematic Diagram of a Rail Gun Thruster ...... 9

3. Schematic Diagram of a MPD Thruster ........ 11

4. Schematic Diagram of a Hydrogen Free Radical

Thruster.............. 13

5. Schematic Diagram of a Mercury Electron Bombardment

Ion Engine . . . . . . . . . . . . 14

6. Overall Efficiency of Mass Driver Versus Projectile Mass for Specific Impulses of 1000 and $1500 \mathrm{sec}$. . 17

7. Effect of Projectile Mass on Input Power of Mass Driver for Specific Impulses of 1000 and $1500 \mathrm{sec}$. . 18

8. Average Thrust of Mass Driver Versus Projectile Mass for Specific Impulses of 1000 and $1500 \mathrm{sec} \ldots 19$

9. Effect of Projectile Mass on Total Length of Mass Driver for Specific Impulses of 1000 and $1500 \mathrm{sec}$. . 20

10. Effect of Projectile Mass on Dry System Mass of Mass Driver for Specific Impulses of 1000 and $1500 \mathrm{sec}$. .

11. Power to Average Thrust Ratio of Mass Driver Versus Projectile Mass for Specific Impulses of 1000 and

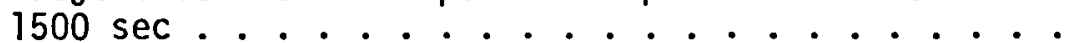

12. Average Thrust to Dry Weight Ratio of Mass Driver Versus Projectile Mass for Specific Impulses of

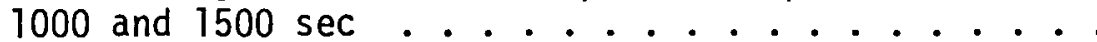

13. Effect of Projectile Mass on Overall Efficiency of Rail Gun for Specific Impulses of 1000, 1500 and

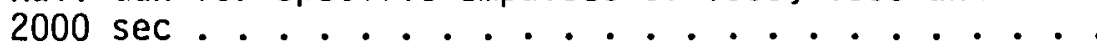

14. Effect of Projectile Mass on Input Power of Rail Gun for Specific Impulses of 1000, 1500 and 2000

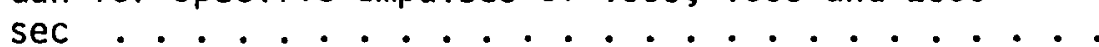

15. Average Thrust of Rail Gun Versus Projectile Mass for Specific Impulses of 1000,1500 and $2000 \mathrm{sec}$. . . 
16. Effect of Projectile Mass on Length of Rail Gun for Specific Impulses of 1000,1500 and $2000 \mathrm{sec}$. . 29

17. Effect of Projectile Mass on Bore Width of Rail Gun ................ 30

18. Effect of Projectile Mass on Current Pulse Requirement of Rail Gun ..............

19. Dry System Mass of Rail Gun Versus Projectile Mass for Specific Impulses of 1000, 1500 and $2000 \mathrm{sec}$. . .

20. Effect of Projectile Mass on Power to Average Thrust Ratio of Rail Gun for Specific Impulses of 1000, 1500 and $2000 \mathrm{sec}$. . . . . . . . . . .

21. Average Thrust to Dry Weight Ratio of Rail Gun Versus Projectile Mass for Specific Impulses of

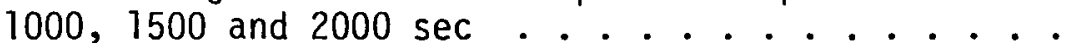

22. Overall Efficiency of MPD Thruster Versus Specific Impulse for Current Pulses of 10, 15 and $20 \mathrm{KA}$. . . 36

23. Input Power of MPD Thruster Versus Specific Impulse for Current Pulses of 10,15 and $20 \mathrm{KA}$.......

24. Average Thrust of MPD Thruster Versus Specific Impulse for Current Pulses of 10, 15 and $20 \mathrm{KA}$. . .

25. Effect of Specific Impulse on Power to Average Thrust Ratio of MPD Thruster for Current Pulses of 10, 15

26. Specific Impulse Versus Molar Ratio of Molecular and Atomic Hydrogen in the Recombination Chamber of Hydrogen Free Radical Thruster . . . . . . . . . . .

27. Thrust Versus Molar Ratio of Molecular and Atomic Hydrogen in the Recombination Chamber of Hydrogen Free Radical Thruster .. . . . . . . . . . . .

28. Input Power Versus Molar Ratio of Molecular and Atomic Hydrogen in the Recombination Chamber of Hydrogen Free Radical Thruster ........... .

29. Power to Thrust Ratio Versus Molar Ratio of Molecular and Atomic Hydrogen in the Recombination Chamber of Hydrogen Free Radical Thruster . . . . . 
30. Effect of Specific Impulse on Overall Efficiency of Mercury Ion Engine ............

31. Effect of Specific Impulse on Input Power of Mercury Ion Engine . . . . . . . . . .

32. Effect of Specific Impulse on Thrust of Mercury Ion Engine ................ 48

33. Effect of Specific Impulse on Dry System Mass of Mercury Ion Engine .............

34. Power to Thrust Ratio of Mercury Ion Engine Versus Specific Impulse ............... 50

35. Thrust to Dry Weight Ratio of Mercury Ion Engine Versus Specific Impulse ............ 51

36. Overall Efficiency of Electric Propulsion Systems Versus Specific Impulse ............ 54

37. Power to Average Thrust Ratio of Electric Propulsion Systems Versus Specific Impulse . . . . . . . 55

38. Average Thrust to Dry Weight Ratio of Mass Driver, Rail Gun and Ion Engine Versus Specific Impulse ... 


\section{INTRODUCTION}

The shuttle based space transportation represents a low cost means of access to geocentric space. This will encourage large scale utilization of space for various activities. ${ }^{1-3}$ The shuttle is expected to form the basis of most of the earth orbital missions for at least the next few decades. This type of transportation is divided into two phases; a high thrust chemical boost phase from earth's surface to place the spacecraft into a low earth orbit (LEO) and subsequent transfer of the payload from LEO to a higher orbit.

All current space transportation systems derive their propulsive forces from chemical rocket engines. However, the quantities of chemical fuel which have to be carried to LEO together with the spacecraft are steadily increasing as a consequence of increasing payloads and increasing mission times. The interest in more efficient propulsion systems derives mainly from the desire of reducing the propellant mass relative to that of the payload.

The specific impulse of the chemical rockets is limited even for the most energetic propellant combinations to below $500 \mathrm{sec}$. Beyond this lies a variety of propulsion modes which promise a specific impulse measured in thousands of seconds. Many of them use electrical energy as input energy and by employing various methods convert part of the input energy into kinetic energy of the masses exhausted from the thrusters. These electric propulsion systems are distinguished by high exhaust velocities, low propellant consumption, low thrust and long operating times. However, after a spacecraft has been placed into a LEO by chemical rockets, high thrust levels are no longer a necessity. Hence, for 
missions not impaired by trip times, low thrust electric propulsion system becomes a preferred candidate.

A number of ideas have been proposed on ways to convert the input electrical energy to kinetic energy of the exhaust beam. One propulsion device which is beyond performance verification stages and close to operational status is the mercury electron bombardment ion thruster. ${ }^{4}$ Most of the others are still in the laboratory experiment or technical concept.stages but a few of them show enough potential to be seriously considered. Some of them are:

1. Linear electromagnetic accelerator or mass driver. ${ }^{5}$

2. DC electric rail gun thruster. ${ }^{6}$

3. Magnetoplasmadynamic (MPD) thruster. ${ }^{7,8}$

4. Free radical thruster. ${ }^{9}$

We report here the results of a study made to establish the performance parameters of these advanced electric propulsion systems and compare them with those of the mercury electron bombardment thrusters. Due to lack of definite information about the operating characteristics and masses of most of the electric propulsion systems, only results of parametric nature are reported. 


\section{ELECTRIC PROPULSION SYSTEMS}

There are basically two different propulsion modes that can be used for upper stage transportations. These are:

1. High thrust chemical propulsion systems to effect orbital transfers in short periods of time (less than a day).

2. Low thrust electric propulsion systems for longer trip times.

High thrust chemical propulsion systems are needed to transfer personnel and priority cargo between orbits. They can make the transfer between LEO and GEO in about half a day or less which allows unshielded transit through the Van Allen radiation belts. Orbital transfer vehicles using chemical rocket engines require about $3 \mathrm{~kg}$ in LEO to place $1 \mathrm{~kg}$ of payload in GEO. 10

Low thrust electric propulsion systems have high propulsive performance with specific impulses of $1000 \mathrm{sec}$ and beyond. Thus, they would require less propellant to perform the same mission. A smaller fuel requirement is always desirable but since this propellant must be delivered from the earth this reduces the overall transportation cost considerably. This is significant, because earth to LEO transportation cost is a major portion of the overall mission cost.

Unlike the chemical rockets where the propulsive energy is contained in the propellant itself, the electric propulsion systems are characterized by an energy source independent of the impulsive mass. Due to the independent energy source, there is no inherent limitation of the specific impulse obtainable from an electric propulsion system. However, for a given thrust the propellant mass is reduced inversely. 
with increasing exhaust velocity, whereas the power and hence, the powerplant mass increase linearly with increasing exhaust velocity. The optimum specific impulse of an electric propulsion system is determined by the characteristic requirements of a specific mission.

Since the source of energy is not contained in the propellant in an electric propulsion system, there are necessarily a number of conversion steps between the primary energy source and the ejected reaction mass as compared to chemical rockets. Some energy is dissipated in each conversion step and this requires that as few conversion steps be incorporated in the propulsion system as possible. Also, each step in the conversion process must be highly efficient to ensure that the kinetic energy of the expelled propellant is not significantly less than the energy output of the power plant.

The conversion of the input electrical energy to the kinetic energy of the ejected propellants can be performed by employing a variety of physical principles. The propulsion systems investigated have thrusters where,

1. the principle of linear synchronous motors and dynamic magnetic levitation are used for acceleration of macroparticles in carriers containing superconducting coils (mass driver).

2. reaction masses are accelerated between parallel rail electrodes by the Lorentz force derived from passing a direct current through the rails (electric rail gun thruster).

3. an energy storage system drives a large current through a flowing gas creating a plasma which is accelerated via the Lorentz force generated by the interaction between the arc current and its self-generated magnetic field (MPD thruster).

4. free radicals are generated by using microwave energy to dissociate hydrogen and recombining and expelling them as exhaust beams (free radical thruster). 
5. electrostatic forces are used to accelerate positive ions of mercury generated by passing an electric arc through mercury vapor (mercury electron bombardment ion thruster). 


\section{SYSTEM DESCRIPTION}

Each system is briefly described in this portion. Readers are referred to appropriate references for information on designs, performances and mission characteristics.

Mass Driver $5,11-14$

The mass driver is a linear electromagnetic accelerator capable of launching reaction masses when designed as a rocket engine. Cylindrical buckets with superconducting coils carrying payloads are accelerated inside a coaxial assembly of drive coils several kilometers long. The payload is released after the desired velocity is achieved and the bucket is decelerated and returned to the starting position along a return track to be used again.

This device behaves essentially as a linear synchronous ac motor. The accelerating force is generated by a travelling magnetic field interacting with a magnetic dipole. The bucket is supported and guided without physical contact with the drive coils by dynamic magnetic levitation.

A small number of drive windings contained in one sector are excited at any given time to minimize power dissipation. A capacitor bank in each sector discharges current through feeders and through silicon-controlled rectifiers (SCR) to the drive windings. A schematic diagram of a mass driver reaction engine is provided in Fig. 1. 


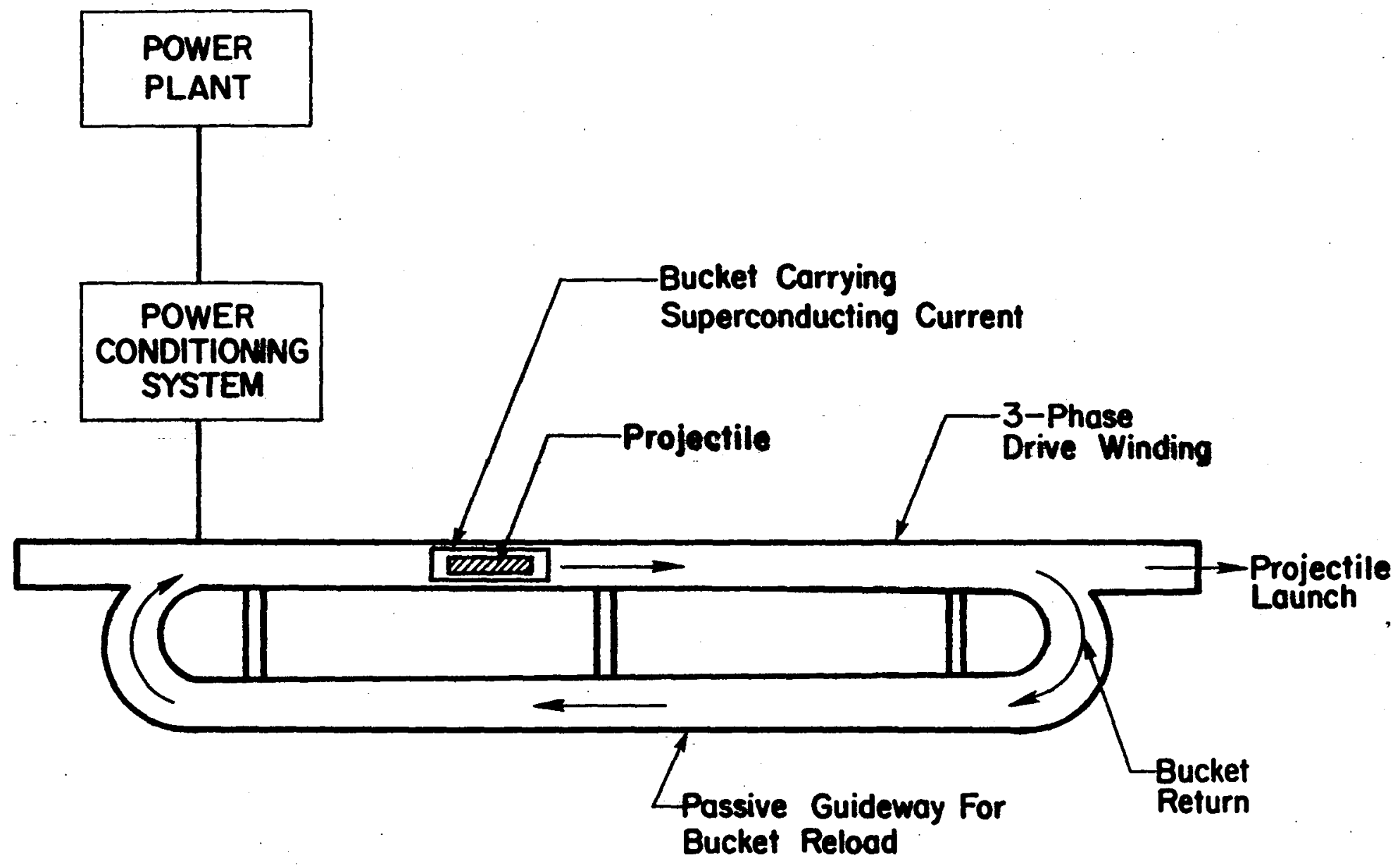

Figure 1. Schematic Diagram of a Mass Driver Reaction Engine. 
Rail Gun Thruster ${ }^{6,15-20}$

The rail gun consists of a pair of parallel conductors separated by a distance and connected by a movable conductor. A large current (kiloamperes) flows in a short burst from one rail to the interconnecting conductor to the other rail. The interconnecting conductor is normally a thin metallic fuse which becomes a plasma when the large current is discharged through it.

The rail gun functions essentially as a linear dc motor. The plasma behaves as an armature while the parallel rails serve as a single turn field winding in series with the armature. The current $\underline{J}$ flowing in the rails generates a magnetic field $\underline{B}$ between the rails and this magnetic field interacts with the current flowing in the armature. The resulting Lorentz force $(\underline{\mathrm{J}} \times \underline{\mathrm{B}})$ acting on the armature accelerates the plasma along the rails. If the plasma is confined behind a projectile made of dielectric materials, the pressure of plasma will accelerate the projectile along with the plasma. The confinement of the plasma can be provided by the conducting rails on two sides and the dielectric materials on the other two sides. The peaking loads are supplied from a capacitor energy storage system and the current is discharged through a pulse shaping network containing an inductor. Fig. 2 shows a schematic drawing of a rail gun thruster.

IMPD Thruster $8,21-24$

The self-field MPD thruster consists of a discharge chamber made of an annular anode ring and a centrally located cathode. After a suitable gaseous propellant, such as argon, is injected into the discharge 


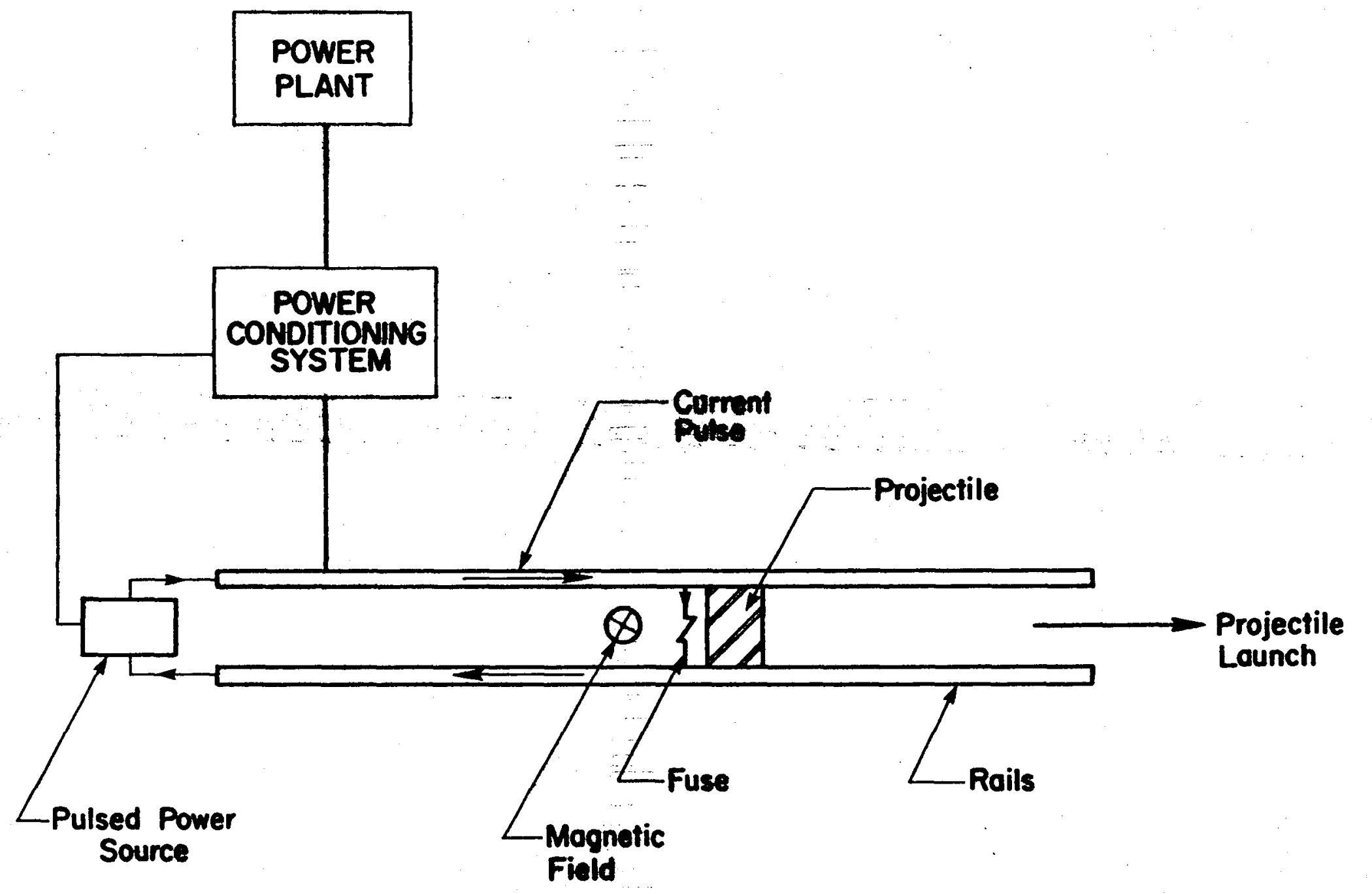

$\infty$

Figure 2. Schematic Diagram of a Rail Gun Thruster. 
chamber, a large current pulse (kiloamperes) is passed from the anode to the cathode ionizing the propellant. A magnetic field $\underline{B}$ is induced inside the discharge chamber by this azimuthally symmetric current flow. It interacts with the current $\underline{\mathrm{J}}$ to induce a Lorentz body force $(\underline{\mathrm{J}} \times \underline{\mathrm{B}})$ on the propellant gas. This Lorentz body force has an axial component which moves the plasma downstream and a radially inward component which confines the plasma. The plasma expelled from the discharge chamber provides the thrust.

The self-field MPD thruster is a low voltage (hundreds of volts), high current device which is well suited for operation in an intermittent, quasi-steady mode. A schematic drawing of a MPD thruster is shown in Fig. 3.

Free Radical Thruster $9,25,26$

This device operates on the principle of continuous creation of atoms dissociated from molecules of light gases, such as hydrogen, and recombining them in a chamber to obtain the heat of recombination of free atoms. The free radical thruster represents the ultimate chemical system yielding the highest specific impulse for one hundred percent dissociation and recombination.

The input electrical energy is converted to microwave radiation and fed into a resonant cavity. Molecular hydrogen gas flows through the cavity and a fraction of the molecules are dissociated by the microwave energy. The mixture of molecular hydrogen and dissociated hydrogen atoms then flows out of the cavity into a recombination chamber where the hydrogen atoms recombine releasing the energy absorbed in dissociation 


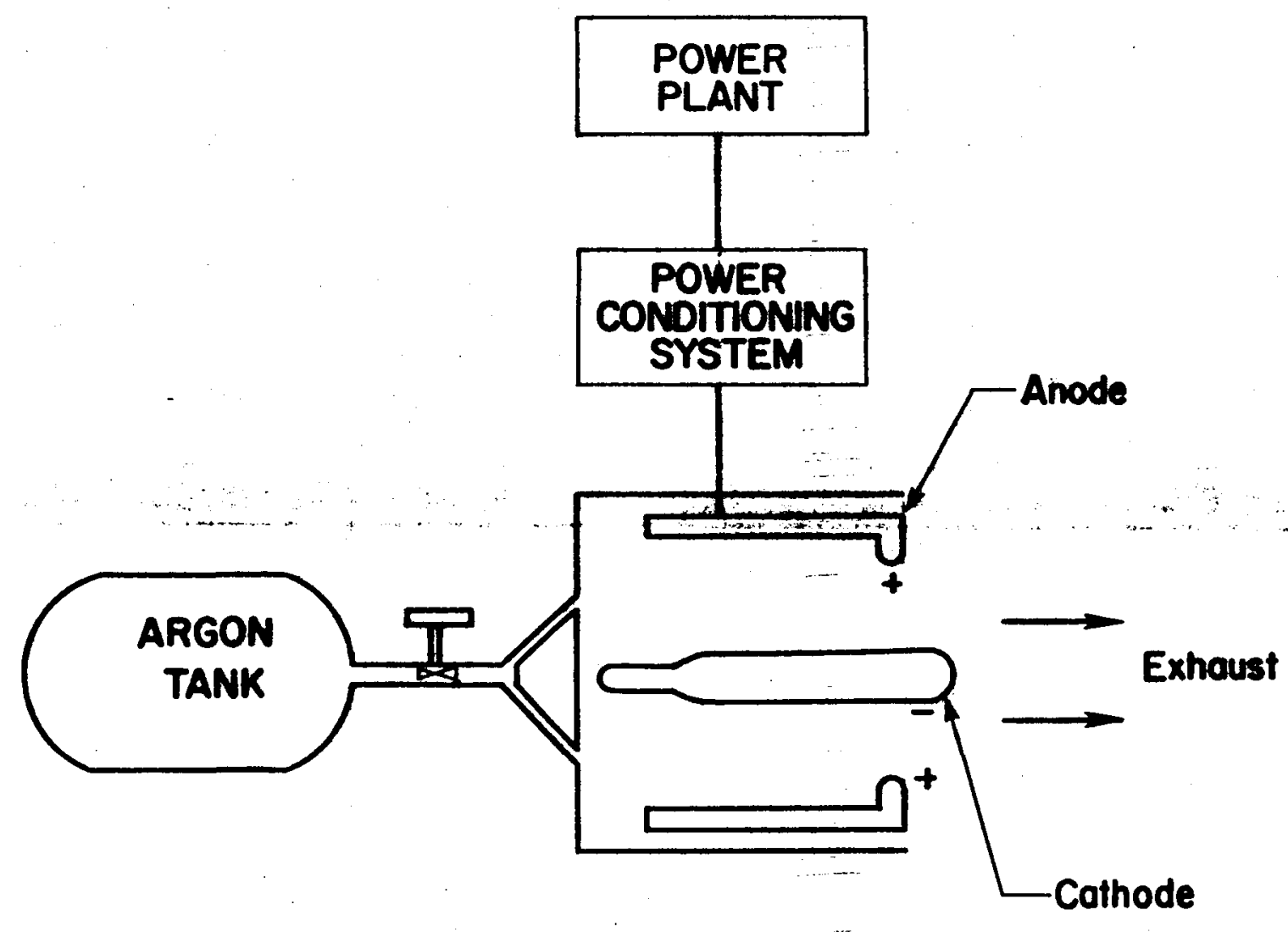

Figure 3. Schematic Diagram of a MPD Thruster. 
as heat. The hot recombined gas is expanded through a nozzle to produce thrust. A schematic diagram of a free radical thruster is shown in Fig. 4.

Mercury Electron Bombardment Ion Thruster $27-29$

In these thrusters, neutral mercury atoms are fed to an ion source and the positive ions generated are accelerated by an electrostatic field. The positive ions are formed through ionization in a discharge chamber by electron bombardment where electrons are emitted from an electrically heated cathode filament and are attracted by a surrounding cylindrical anode. The electrons are made to spiral through mercury vapor by applying an axially divergent magnetic field to improve ionization efficiency.

The positive ions are extracted and accelerated by a multipleaperture dished accelerator screen grid system. The first electrode is maintained at a negative potential with respect to the ion source and the second electrode is kept slightly positive with respect to the first one. After being expelled from the thruster the positive ion beam is neutralized by the addition of an equal number of negative electrons. Fig. 5 shows a schematic drawing of an ion thruster. 


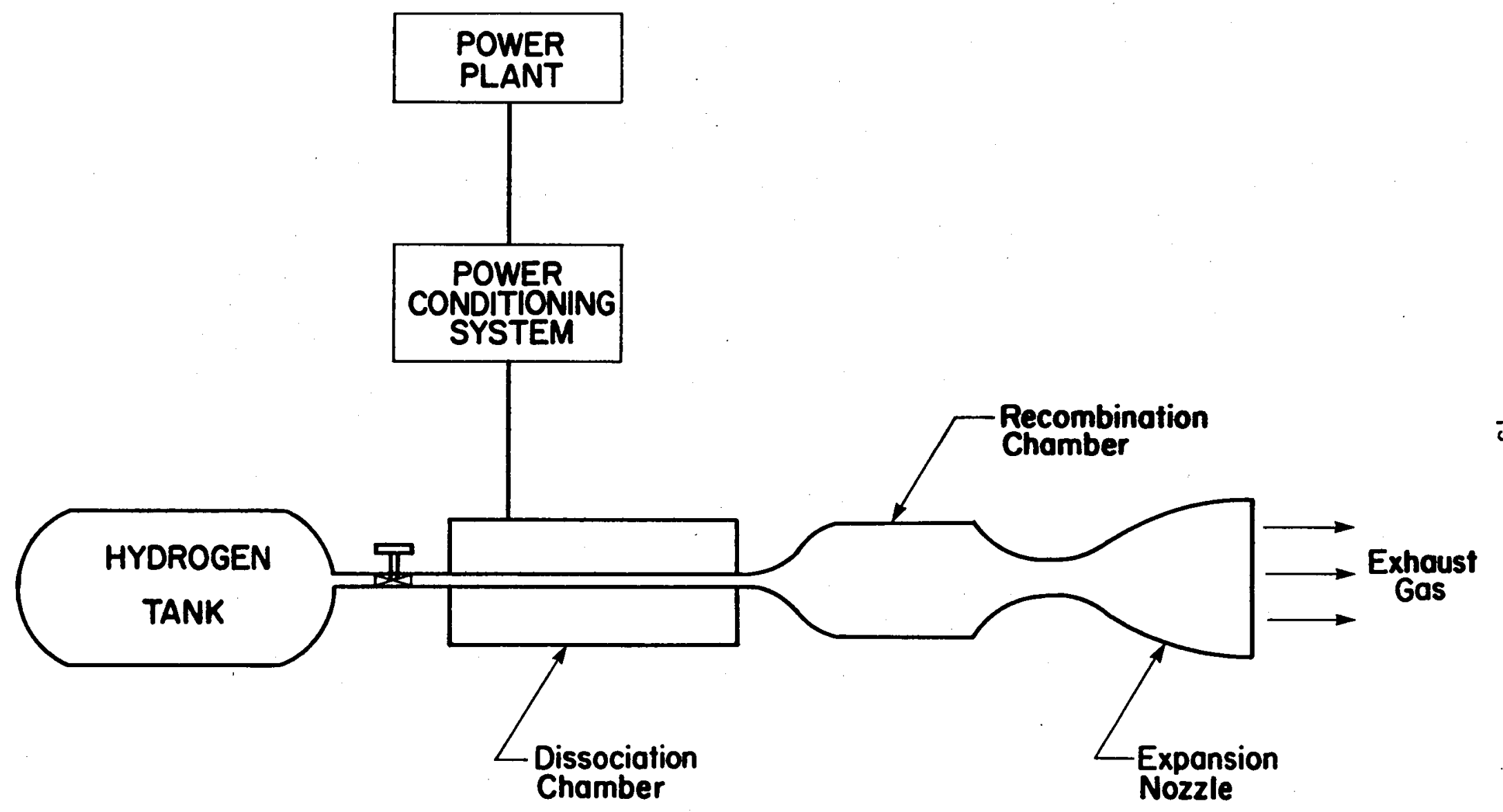

Figure 4. Schematic Diagram of a Hydrogen Free Radical Thruster. 


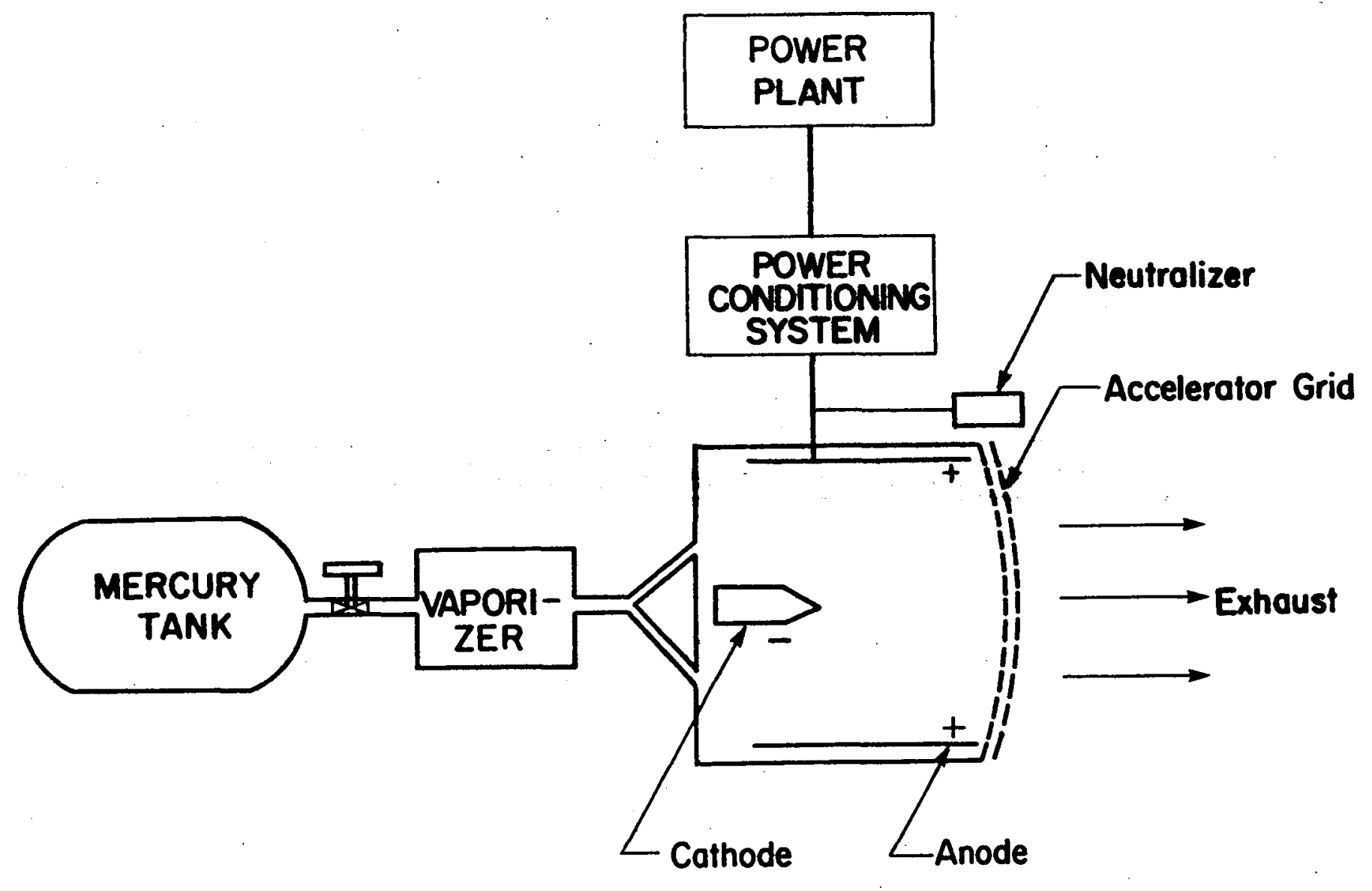

Figure 5. Schematic Diagram of a Mercury Electron Bombardment Ion Engine. 
RESULTS

For a comparative evaluation, the electric propulsion systems are characterized by specific impulse, overall efficiency, input power requirement, thurst, power to thrust ratio and thrust to weight ratio. For propulsion systems operating in an impulsive mode, the pertinent characteristics are specific impulse, overall efficiency, input power, average thrust, power to average thrust ratio and average thrust to dry weight ratio. Besides, there are several important physical characteristics such as dry system mass, accelerator length, bore size and current pulse requirement and these are also evaluated in appropriate cases.

Overall efficiency is obtained by dividing the average kinetic power output of the exhaust beam by the required input power from the power plant. The average thrust is calculated by using the equations outlined in the appendices. Dry system mass and dry weight represent the masses and weights of all components except fuel.

The efficiency of the power conditioning system has been assumed to be 0.9 in all cases except ion engine. The power plant specific mass is assumed to be $10 \mathrm{~kg} / \mathrm{kw}$. For mass driver and rail gun, the radiator specific mass is assumed to be $10 \mathrm{~kg} / \mathrm{kw}$ and the power conditioning system mass is assumed to be $5 \mathrm{~kg}$ per kilowatt of input power. It is to be noted that these values are quite optimistic. Characteristics of each of the five electric propulsion systems are presented in the following sections.

Mass Driver

For the purpose of this study, we have selected a reference design of a coaxial mass driver reaction engine by 0 'Neill. ${ }^{12}$ In this 
design, the diameter of the drive winding is set at $5 \mathrm{~cm}$ and that of the bucket is $1.3 \mathrm{~cm}$. The mass of the bucket is $22 \mathrm{gm}$ and it can carry $25,000 \mathrm{amp} / \mathrm{cm}^{2}$ at superconducting temperature. The peak drive current is 7,580 amp-turns. The frequency of launch is taken to be $5 \mathrm{~Hz}$. The equations and data used to calculate the characteristics of mass driver are presented in Appendix A.

For this mass driver design, projectile mass and specific impulse are used as the variables. The mass of the projectile is varied from $1 \mathrm{gm}$ to $30 \mathrm{gm}$ for two values of specific impulse, $1000 \mathrm{sec}$ and $1500 \mathrm{sec}$. Mass driver characteristics are determined for several combinations of projectile mass and specific impulse.

Overall efficiency of the mass driver is plotted in Fig. 6 against projectile mass for the two specific impulses. It is observed that the efficiency is quite low for smaller projectile masses. However, it rapidly rises to a high value (greater than 50 percent) and begins to flatten out thereafter. The efficiency is higher when mass drivers are operated at higher specific impulse.

Figures 7 and 8 show the effect of variation of projectile mass on the input power and the average thrust of the mass driver. The input power requirement ranges from a megawatt to tens of megawatts and the average thrust varies from tens of newtons to thousands of newtons. These devices are extremely long (tens of kilometers, fig. 9) and hence, very massive (Fig. 10).

The power to average thrust ratio is presented in Fig. 11. This ratio is rather high at low projectile masses and approaches an asymptotic value $\left(\sim 9 \mathrm{kw} / \mathrm{N}\right.$ at $\mathrm{I}_{\mathrm{sp}}=1500 \mathrm{sec}$ and $\sim 6 \mathrm{kw} / \mathrm{N}$ at $\left.\mathrm{I}_{\mathrm{sp}}=1000 \mathrm{sec}\right)$ as 


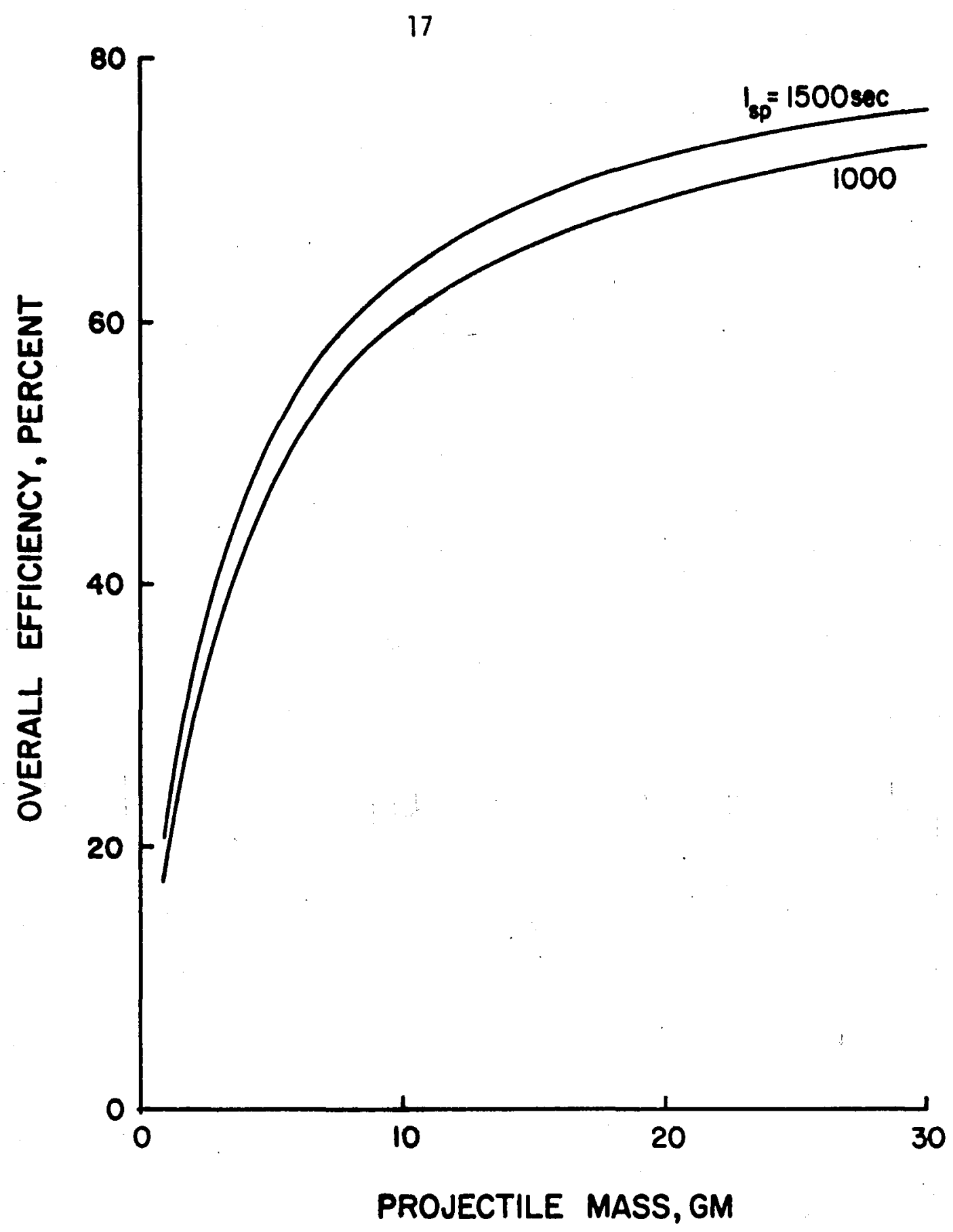

Figure 6. Overall Efficiency of Mass Driver Versus Projectile Mass for Specific Impulses of 1000 and $1500 \mathrm{sec}$. 


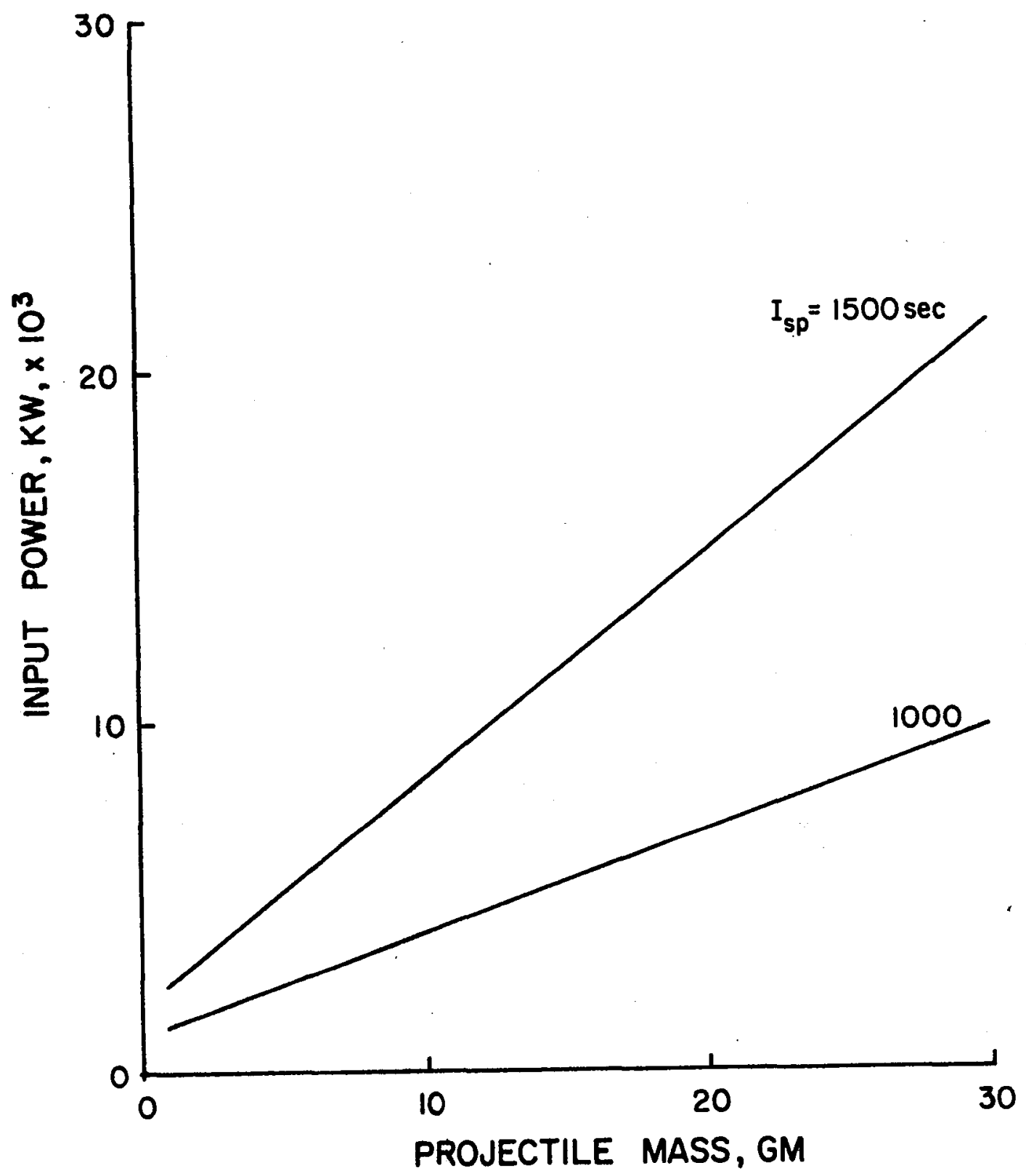

Figure 7. Effect of Projectile Mass on Input Power of Mass Driver for Specific Impulses of 1000 and $1500 \mathrm{sec}$. 


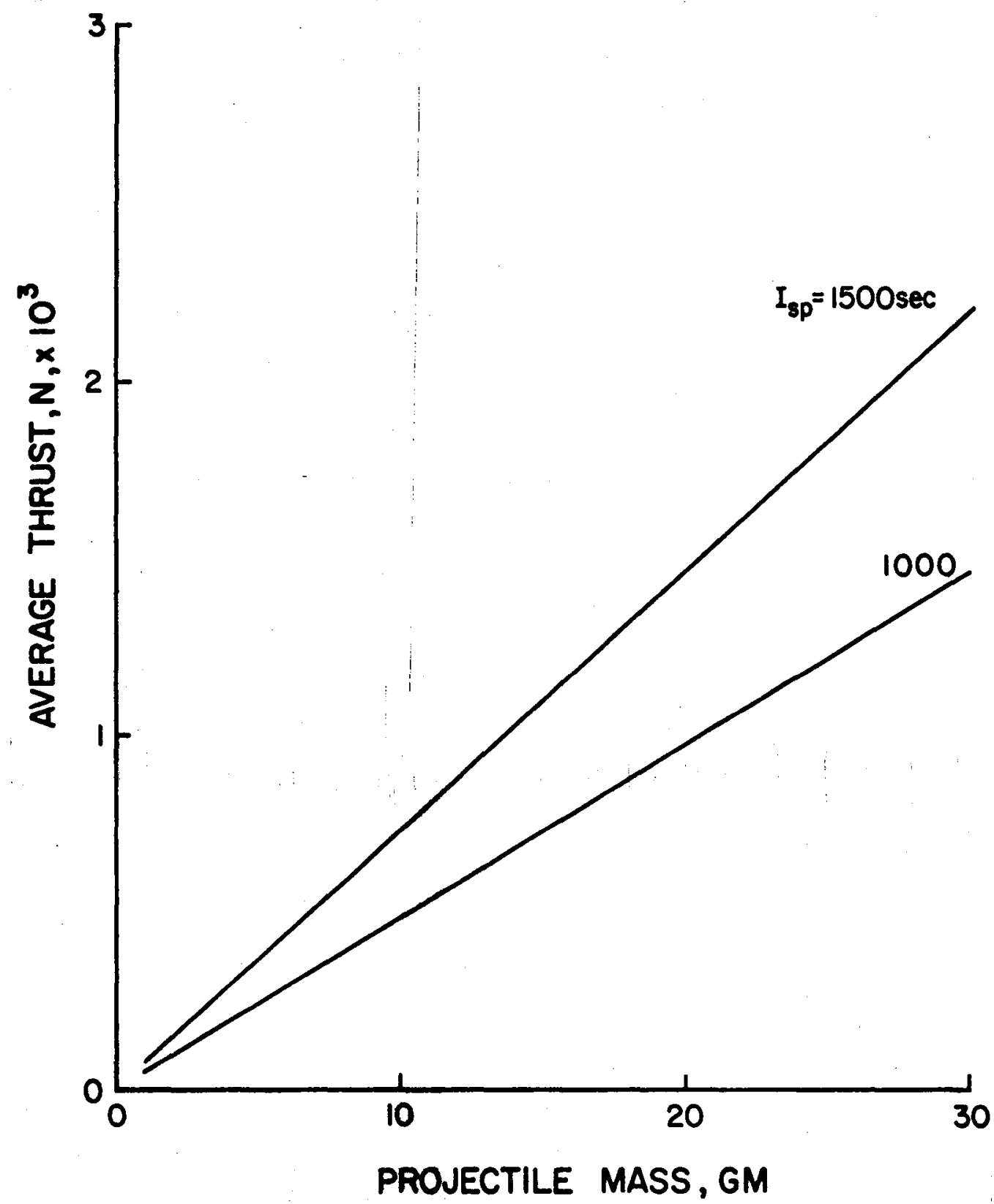

Figure 8. Average Thrust of Mass Driver Versus Projectile Mass for Specific Impulses of 1000 and $1500 \mathrm{sec}$. 


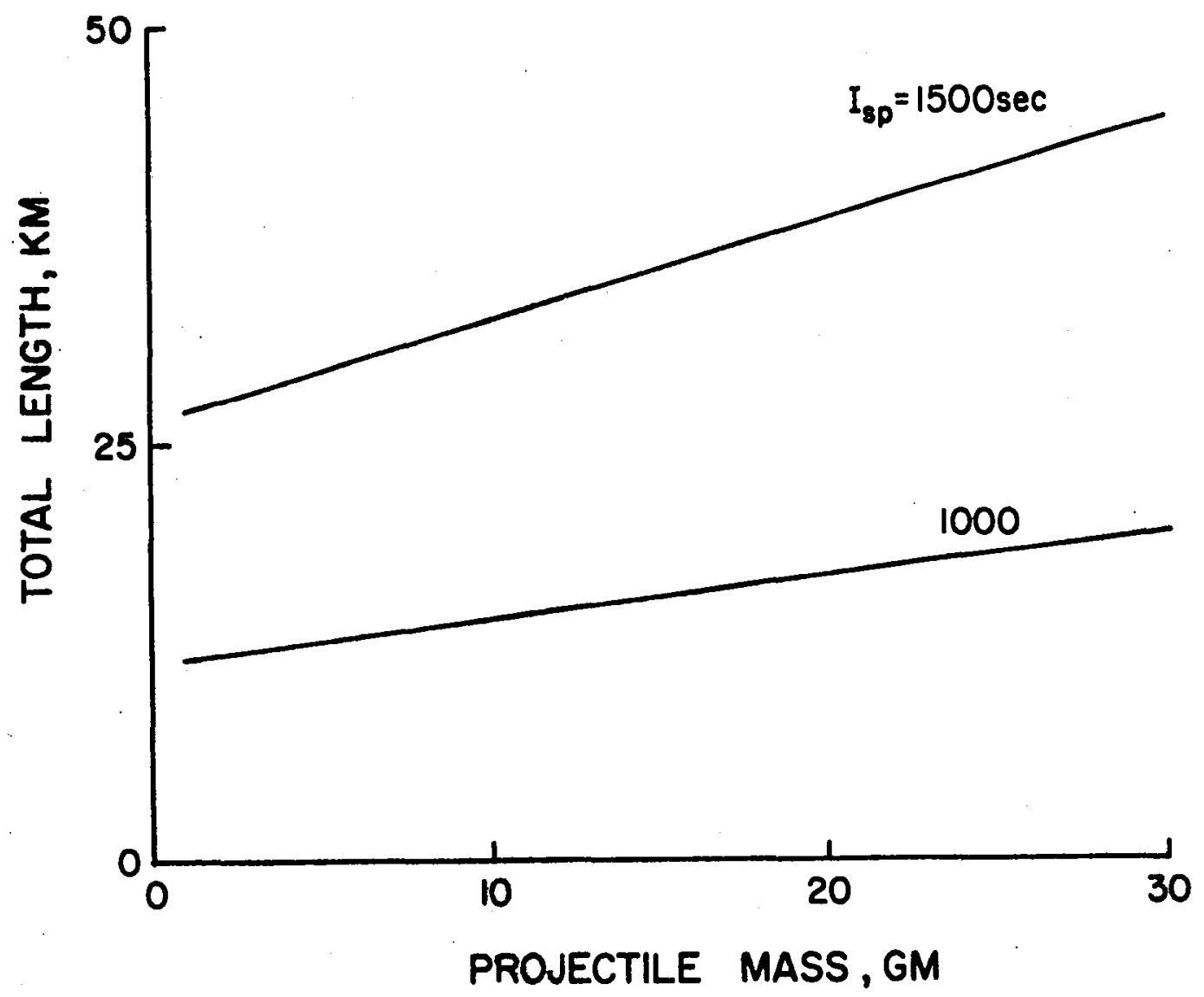

Figure 9. Effect of Projectile Mass on Total Length of Mass Driver for Specific Impulses of 1000 and $1500 \mathrm{sec}$. 


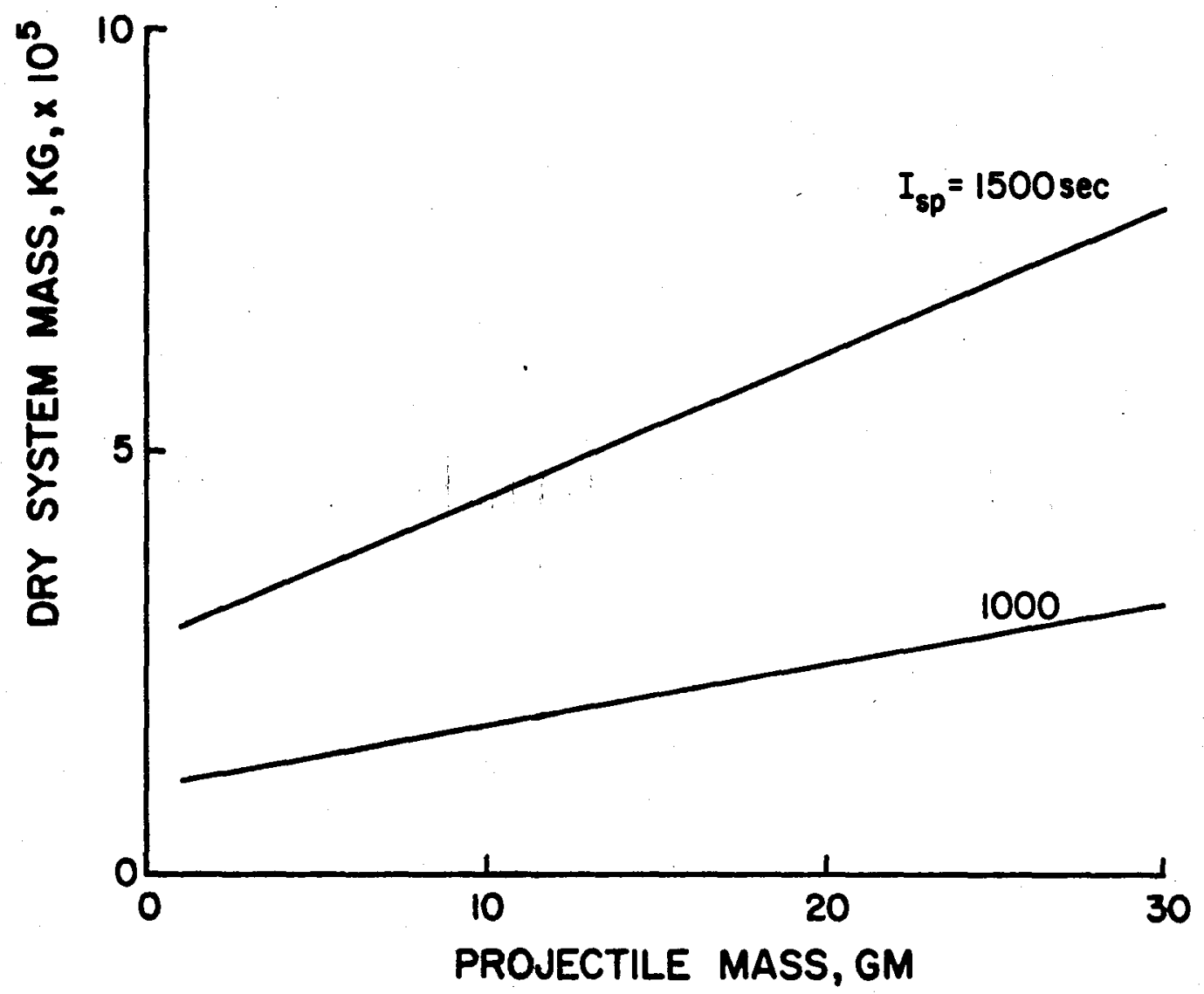

Figure 10. Effect of Projectile Mass on Dry System Mass of Mass Driver for Specific Impulses of 1000 and $1500 \mathrm{sec}$. 


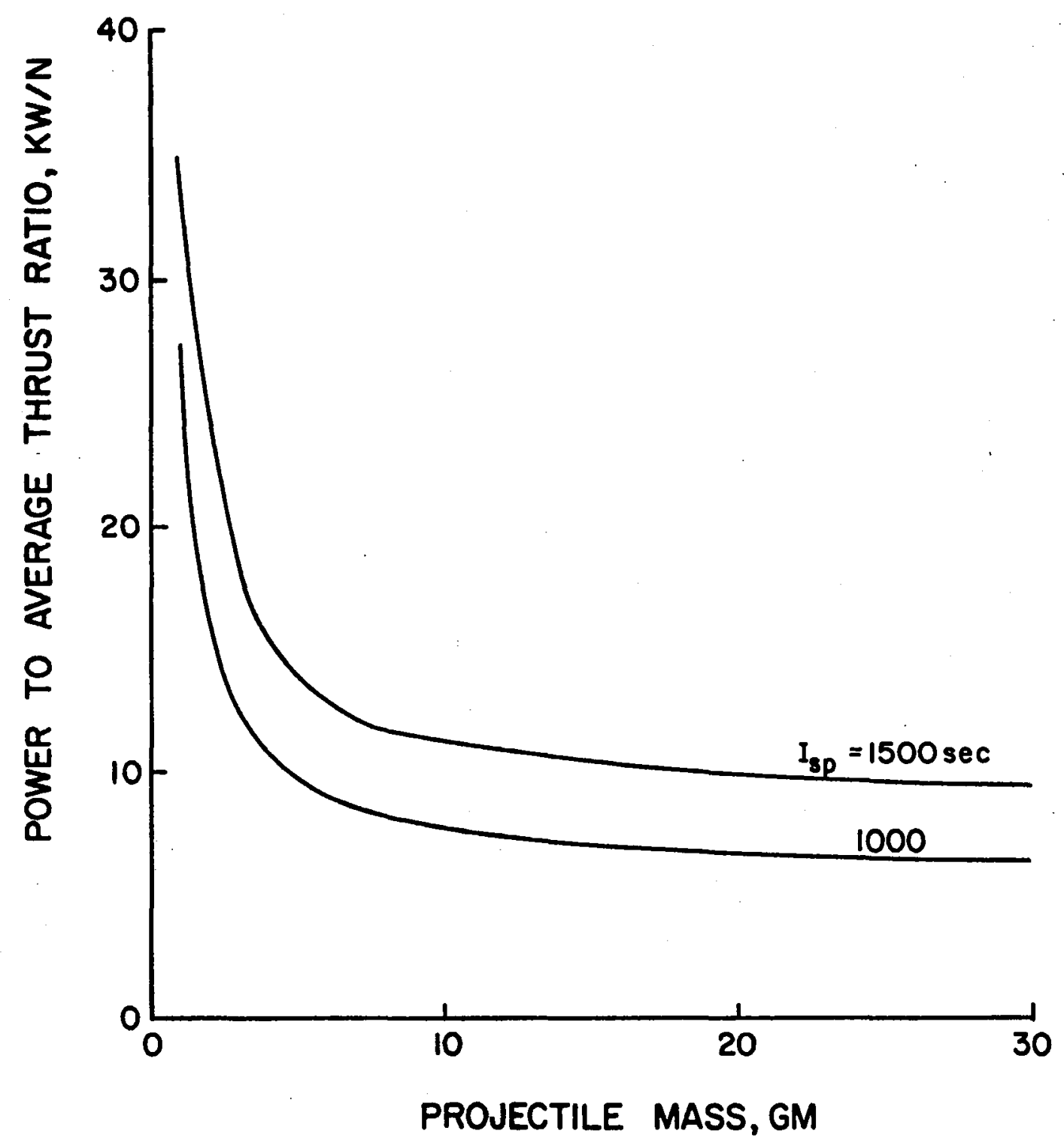

Figure 11. Power to Average Thrust Ratio of Mass Driver Versus Projectile Mass for Specific Impulses of 1000 and $1500 \mathrm{sec}$. 
the mass of the projectile is increased. Figure 12 shows the average thrust to dry weight ratio of the mass driver. For a fixed specific impulse, it increases with increase in projectile mass. This ratio decreases when specific impulse is increased.

\section{Rail Gun Thruster}

The characteristics of rail gun thrusters have been evaluated by using the correlations developed by Bauer et al. ${ }^{19}$ The accelerator is assumed to have a square bore and the projectile thickness is assumed to be half of the bore width. To withstand high stresses due to rapid acceleration, the projectile is assumed to be made of a composite of

resin and graphite fiber having a density of $2,200 \mathrm{~kg} / \mathrm{m}^{3}$. The launching frequency is taken to be $5 \mathrm{~Hz}$. The equations used in calculating the rail gun characteristics are provided in Appendix $B$.

Projectile mass and specific impulse are used as the variables in rail gun calculations. The mass of the projectile is varied from $0.1 \mathrm{gm}$ to $1.0 \mathrm{gm}$ for specific impulses of 1000,1500 and $2000 \mathrm{sec}$. Characteristics of rail guns are evaluated for several combinations of projectile mass and specific impulse.

Figure 13 shows the overall efficiency of the rail gun against projectile mass for the three specific impulses. It can be seen that the efficiency is rather low; the upper limit is close to 34 percent. At a fixed specific impulse, the efficiency increases with the increase of projectile mass. However, the efficiency progressively decreases as the specific impulse is increased. 


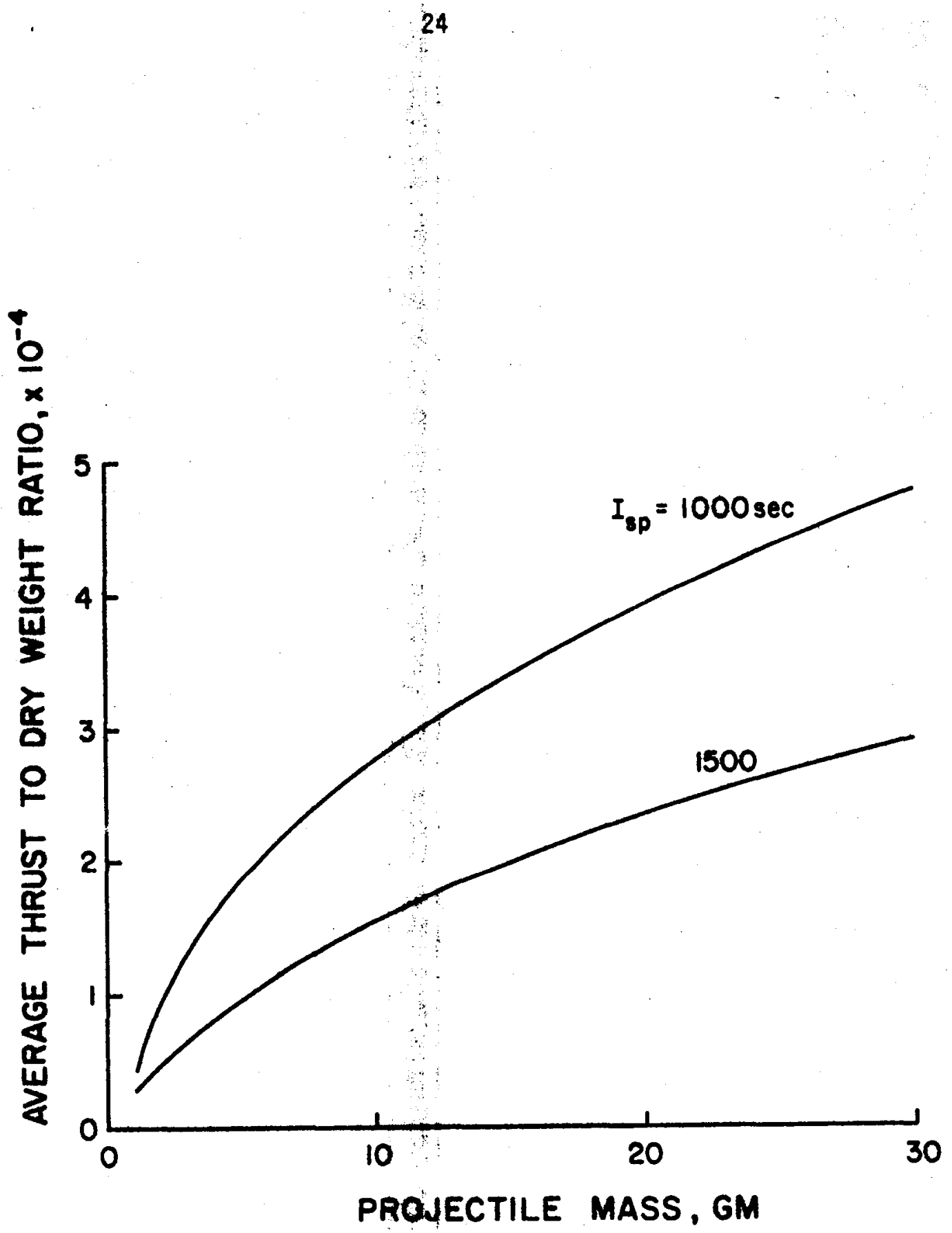

Figure 12. Average Thrust to Dry Weight Ratio of Mass Driver Versus Projectile Mass for Specific Impulses of 1000 and $1500 \mathrm{sec}$. 


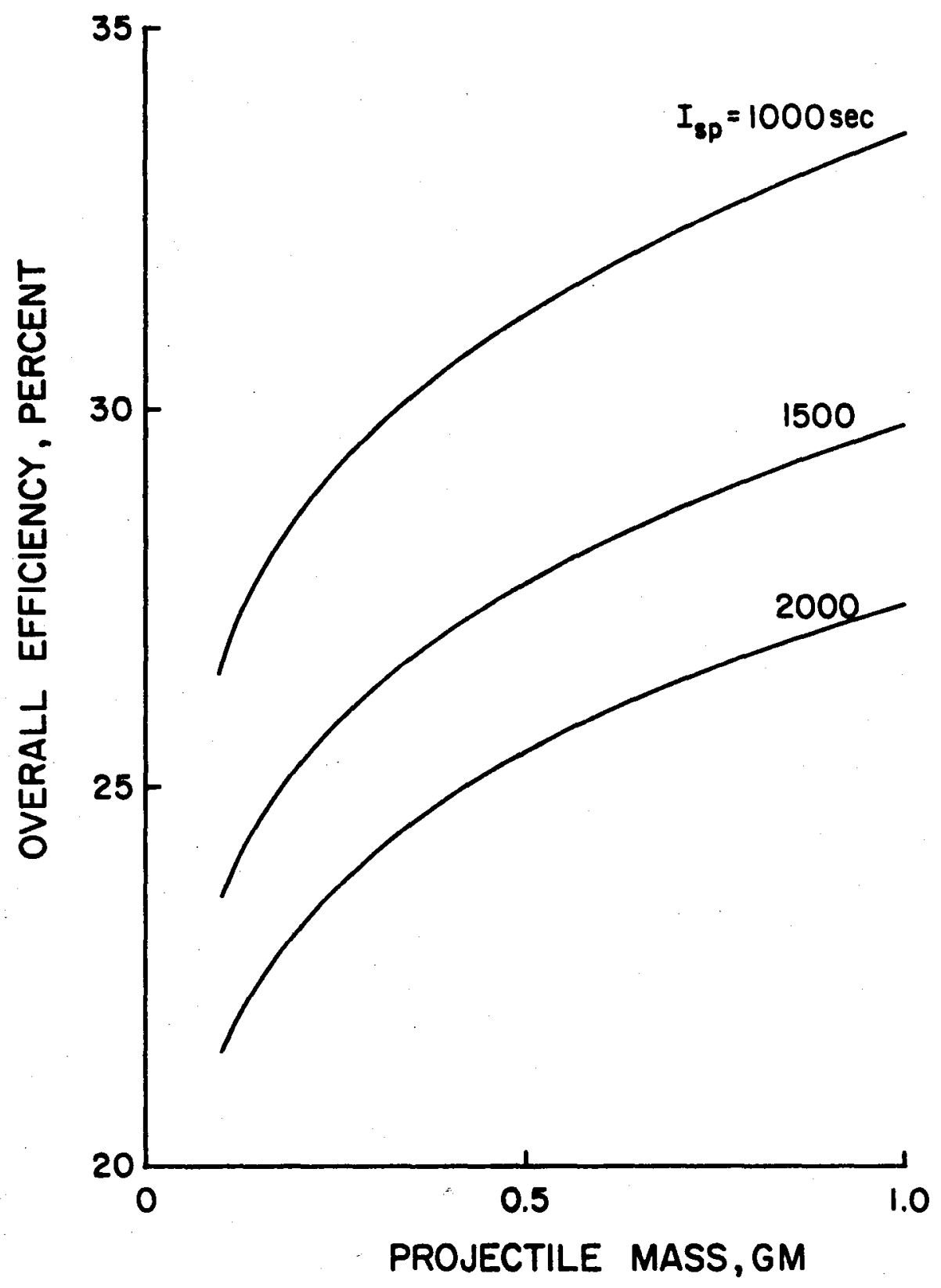

Figure 13. Effect of Projectile Mass on Overall Efficiency of Rail Gun for Specific Impulses of 1000, 1500 and $2000 \mathrm{sec}$. 
The effect of variation of projectile mass on the input power and average thrust of the rail gun is seen in Fig. 14 and Fig. 15 respectively. At low specific impulse and small projectile mass the input power requirement is hundreds of kilowatts and the average thrust is tens of newtons. For gram size projectiles at higher specific impulse, the input power requirement quickly climbs to the megowatt level and the average thrust increases to hundreds of newtons. To achieve higher efficiency, rail guns should be operated at a low specific impulse and a high average thrust (hence, a high input power).

The length of the rail gun varies from tens to hundreds of meters to provide a specific impulse of $1000 \mathrm{sec}$ or more (Fig. 16). Figure 17 indicates the required bore size and it is clear that masses less than $0.1 \mathrm{gm}$ can not be launched from a practical point of view as the bore width has to be less than $4 \mathrm{~mm}$ for a $20 \mathrm{~m}$ long accelerator. Current pulses requiredin rail guns vary from $35 \mathrm{KA}$ for launching a mass of $0.1 \mathrm{gm}$ to $75 \mathrm{KA}$ for launching a mass of $1.0 \mathrm{gm}$ (Fig. 18). For a given projectile mass, changing specific impulse has no significant effect on the length and bore size of the accelerator and the current pulse needed. The dry system mass of the rail gun thruster is presented in Fig. 19. Due to low efficiency of the rail gun, the power to average thrust ratio of this device is rather high, particularly at specific impulses of 1500 and $2000 \mathrm{sec}$ (Fig. 20). For a given specific impulse, this ratio decreases slowly as the projectile mass is increased. The average thrust to dry weight ratio is presented in Fig. 21 . For a given specific impulse, it increases slowly with increase in projectile mass. This ratio decreases when specific impulse is increased. 


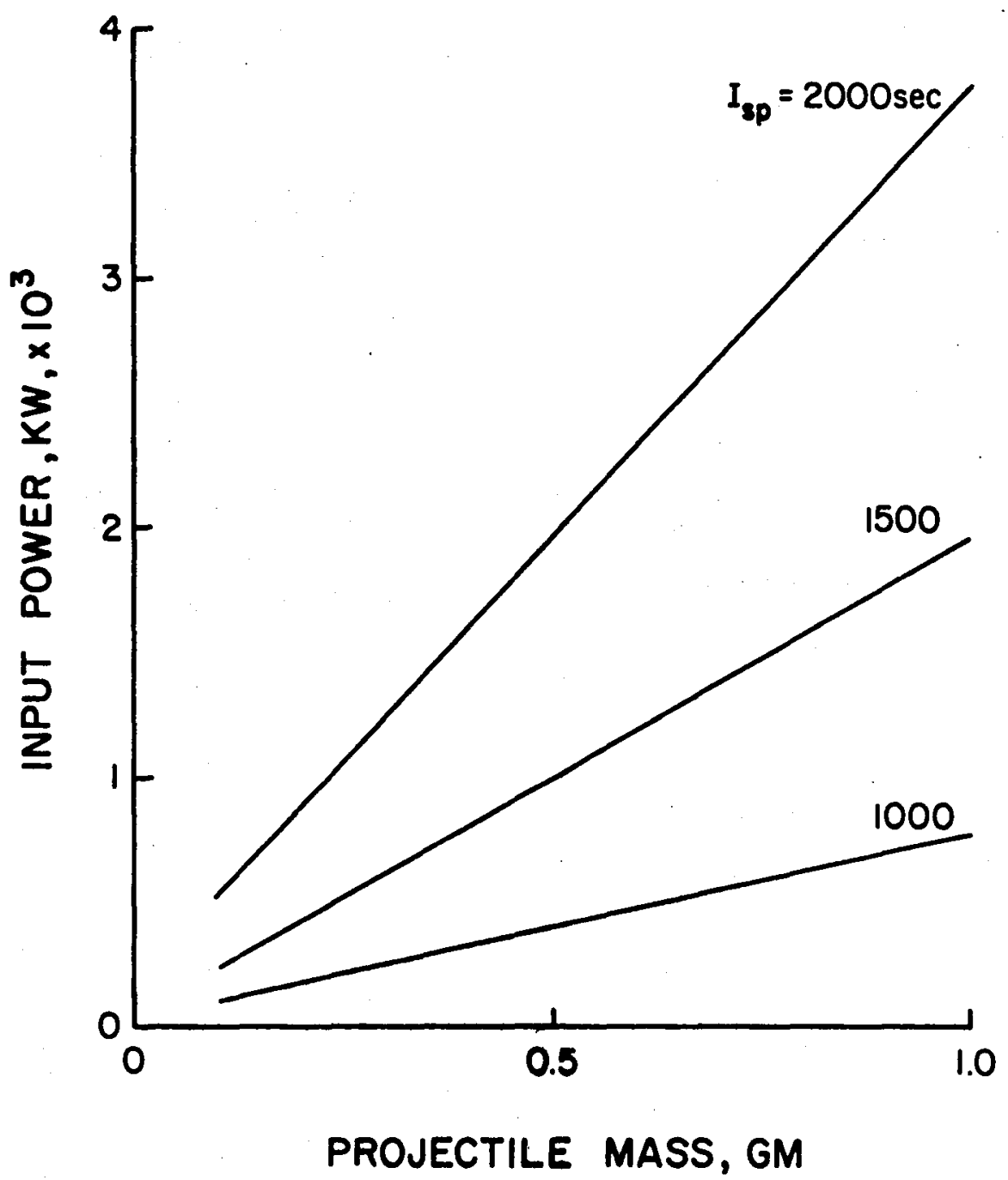

Figure 14. Effect of Projectile Mass on Input Power of Rail Gun for Specific Impulses of 1000, 1500 and $2000 \mathrm{sec}$. 


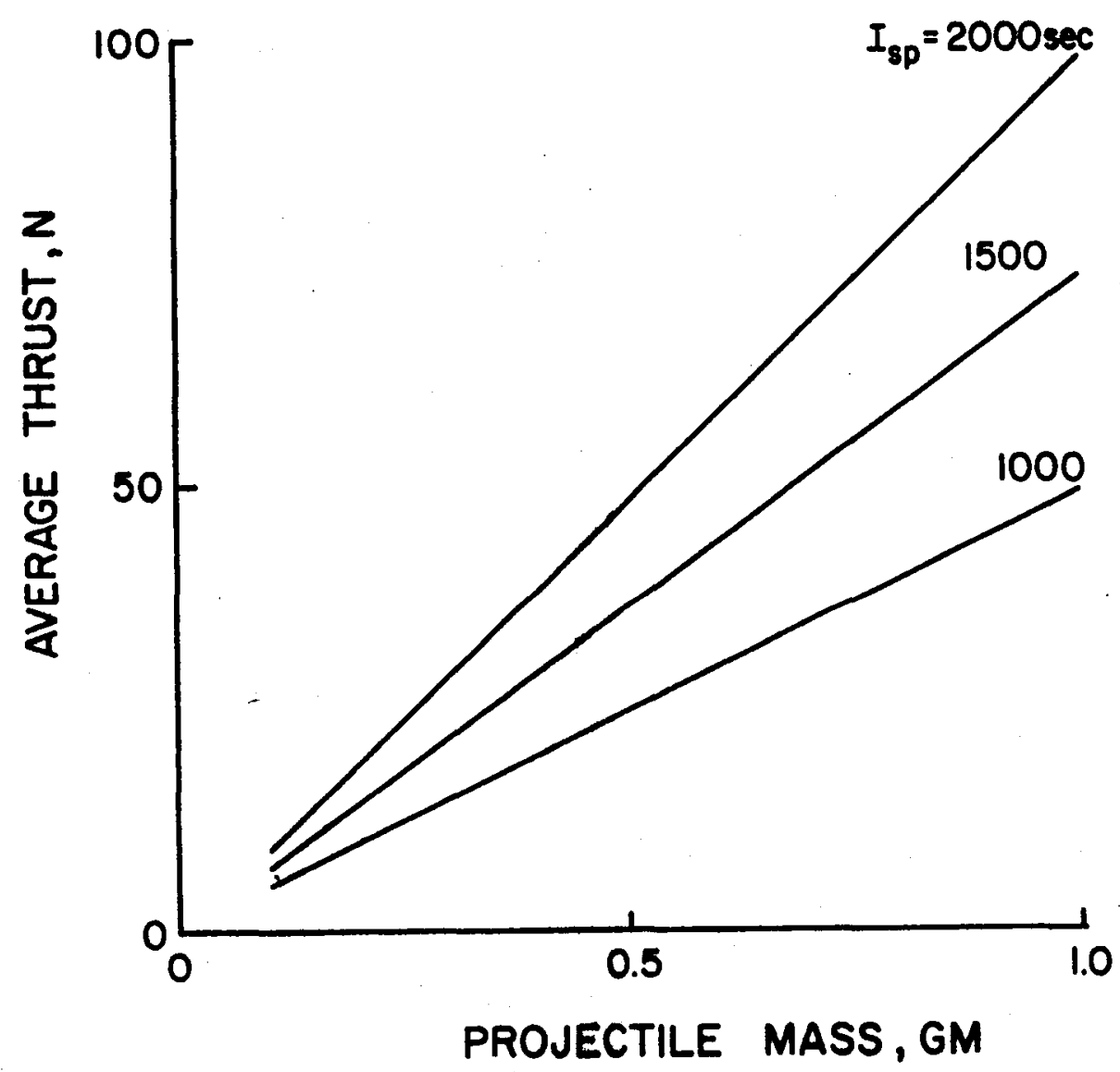

Figure 15. Average Thrust of Rafl Gun Versus Projectile Mass for Specific Impulses of 1000,1500 and $2000 \mathrm{sec}$. 


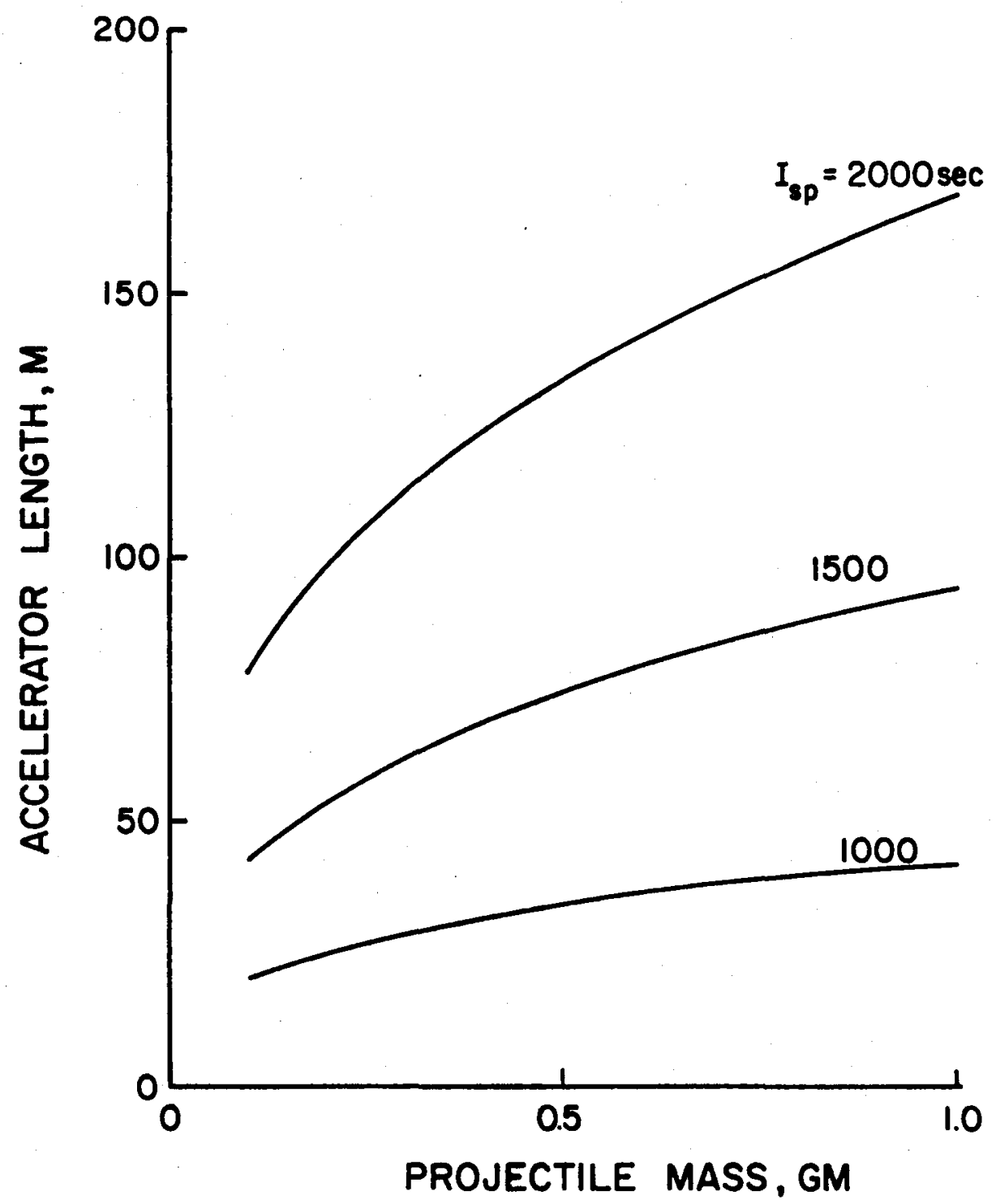

Figure 16. Effect of Projectile Mass on Length of Rail Gun for Specific Impulses of 1000,1500 and $2000 \mathrm{sec}$. 


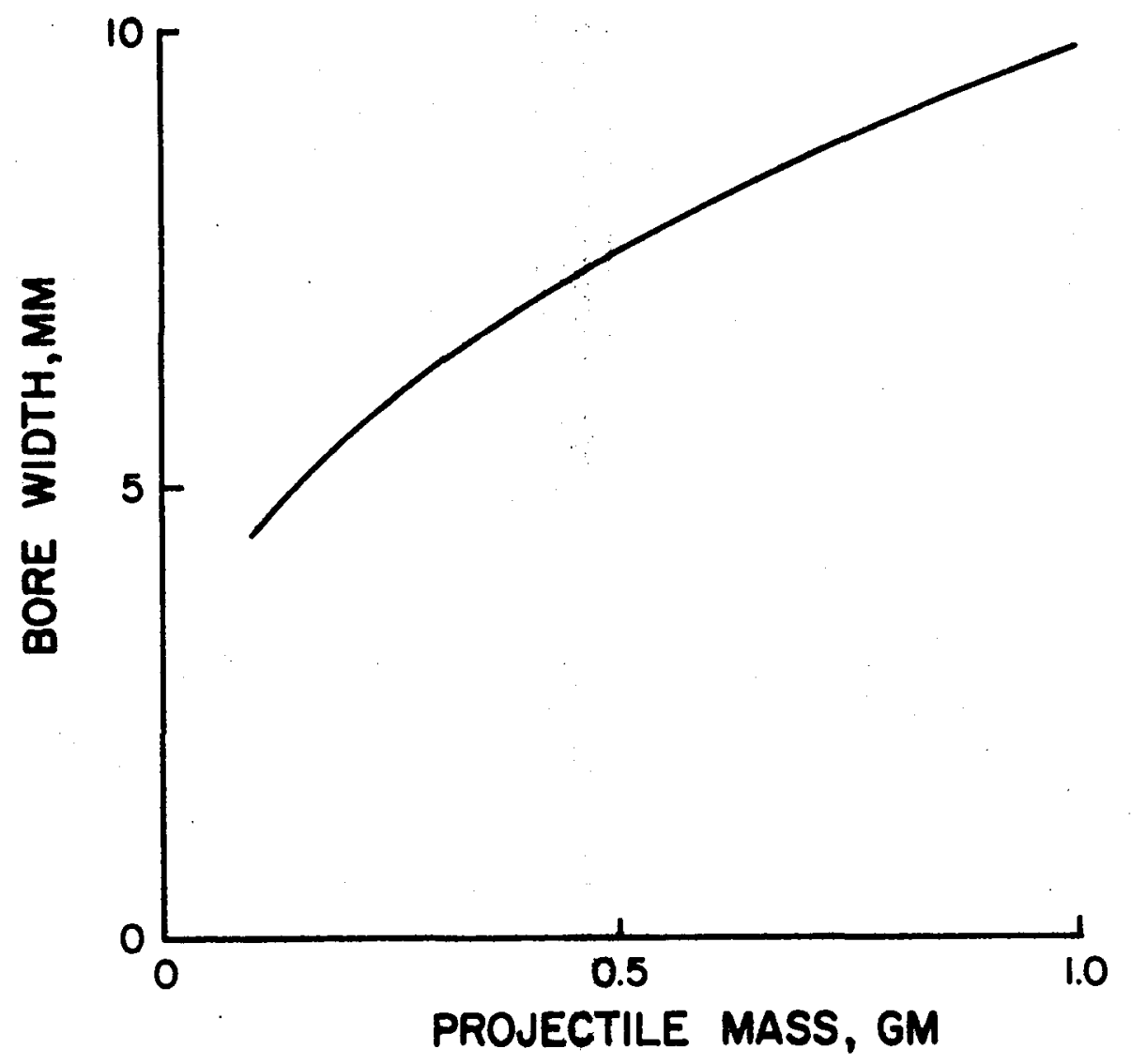

Figure 17. Effect of Projectile Mass on Bore Width of Rail Gun. 


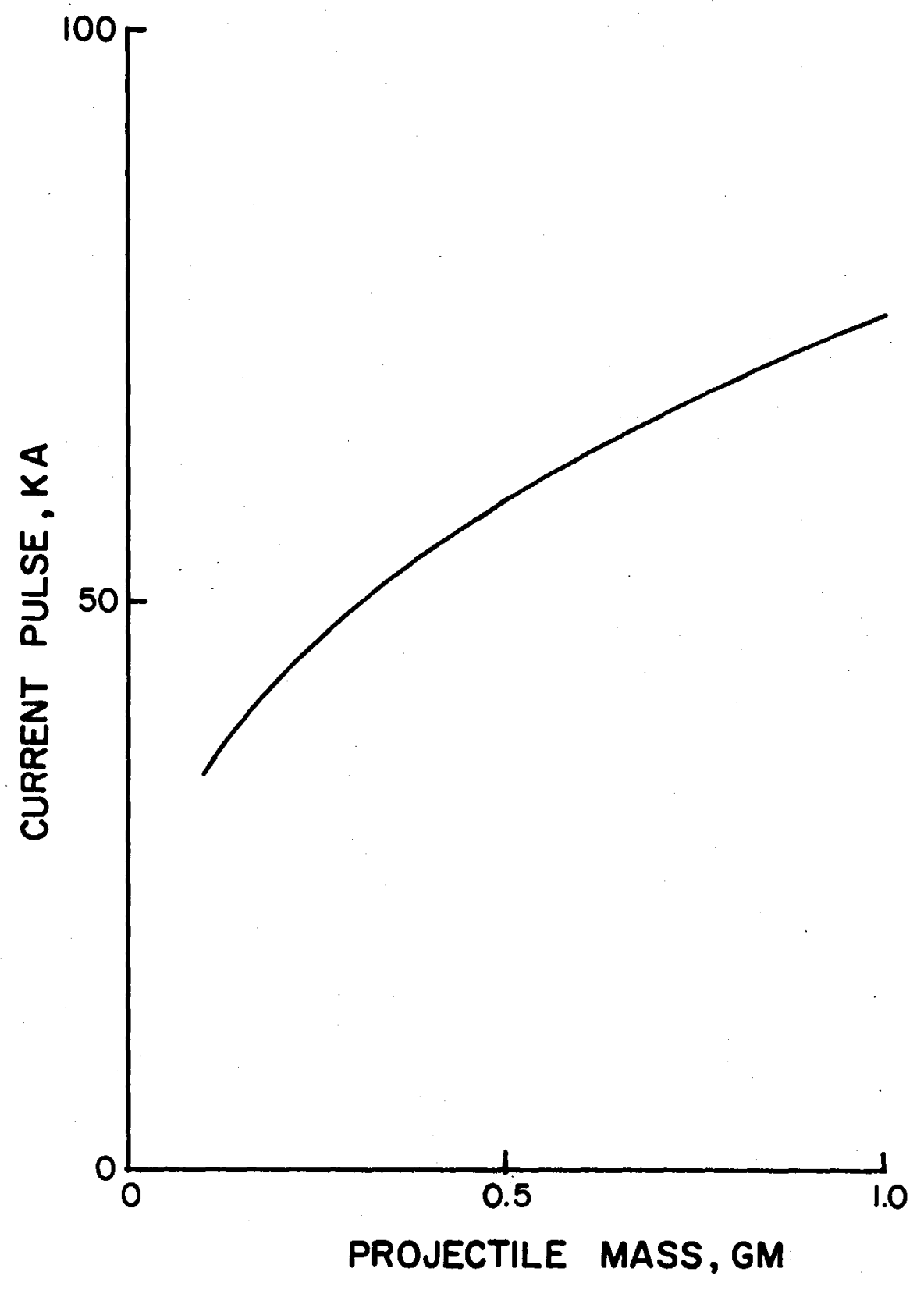

Figure 18. Effect of Projectile Mass on Current Pulse Requirement of Rail Gun. 


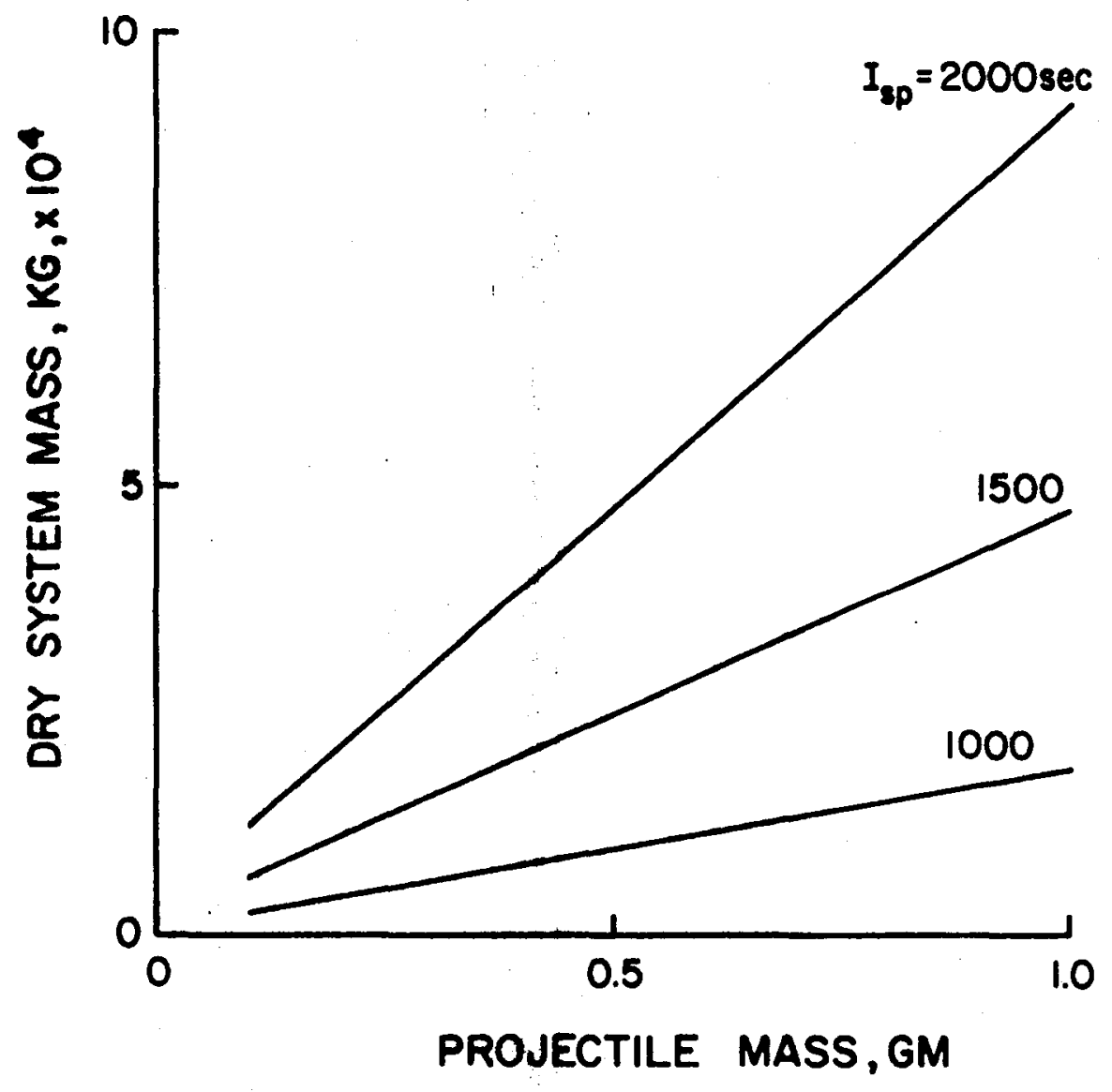

Figure 19. Dry System Mass of Rail Gun Versus Projectile Mass for Specific Impulses of 1000,1500 and $2000 \mathrm{sec}$. 


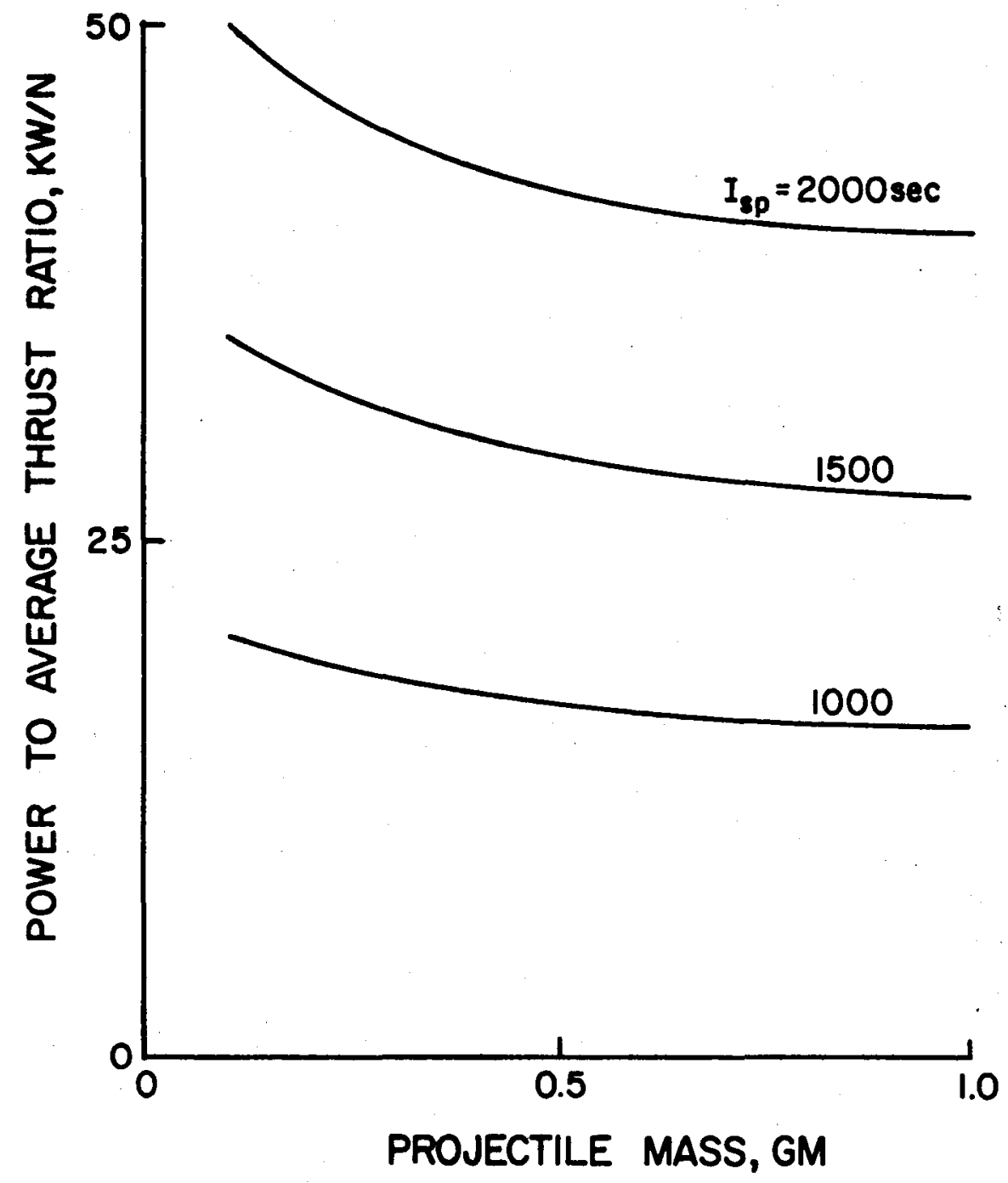

Figure 20. Effect of Projectile Mass on Power to Average Thrust Ratio of Rail Gun for Specific Impulses of 1000, 1500 and 2000 sec. 


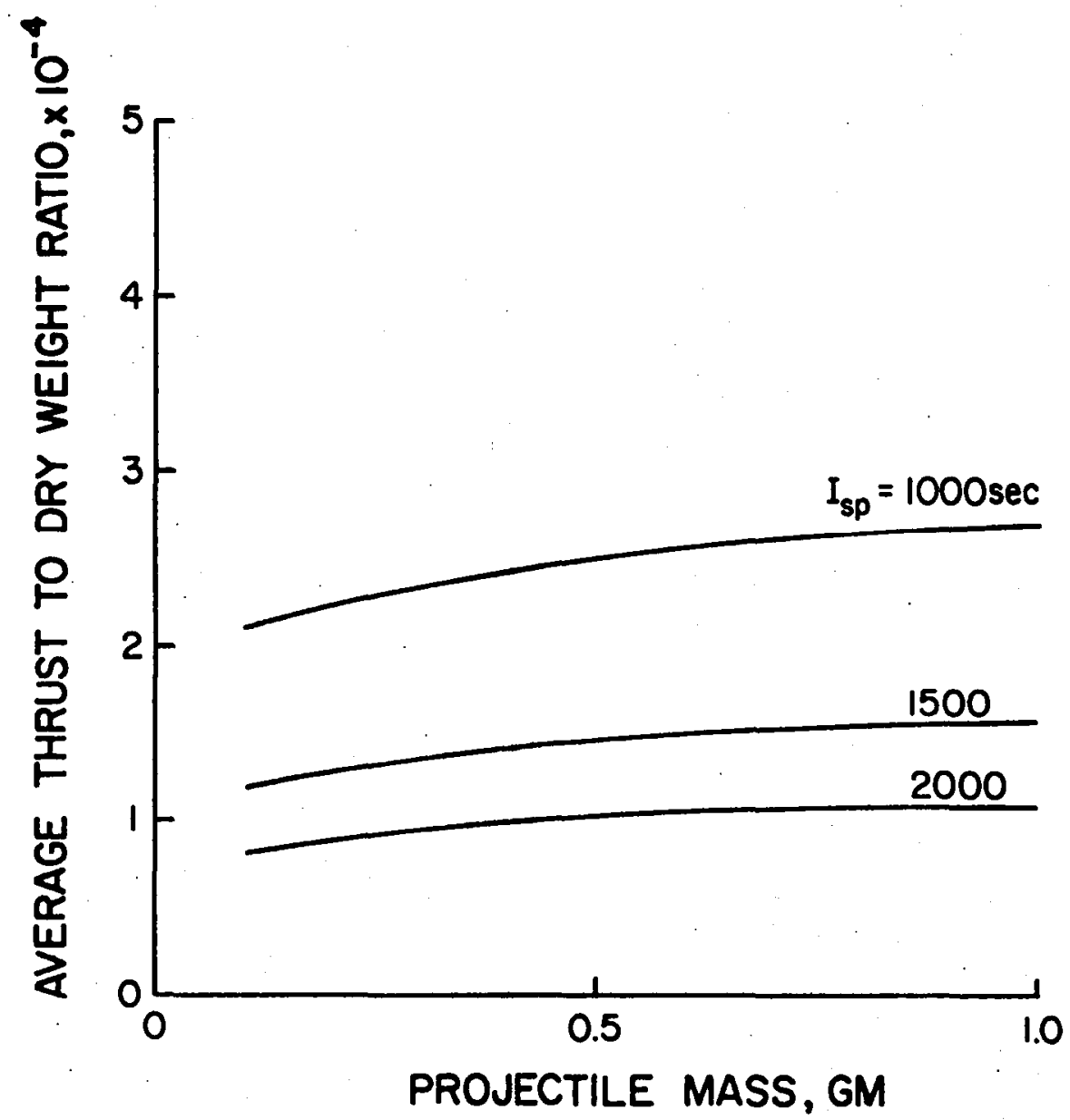

Figure 21. Average Thrust to Dry Weight Ratio of Rail Gun Versus Projectile Mass for Specific Impulses of 1000, 1500 and $2000 \mathrm{sec}$. 
MPD Thruster

The MPD thruster characteristics are evaluated by using the experimental data obtained from an argon self-field MPD device. ${ }^{8}$ Current impulses in the range of 10 to $20 \mathrm{KA}$ and average gas flows in the range of 7.5 to $9.0 \mathrm{gm} / \mathrm{sec}$ have been used in these experiments to provide specific impulses from 200 to $2200 \mathrm{sec}$. The thruster terminal voltage ranged from 40 to 155 volts. The data used represent the operating range before the onset of the voltage fluctuations. We have assumed that the current discharge lasts for $1 \mathrm{msec}$ and the charging time is $9 \mathrm{msec}$. The cycle time is thus $10 \mathrm{msec}$. The equations used to determine the MPD thruster characteristics are presented in Appendix $C$.

Overall efficiency of MPD thruster is plotted against specific impulse in Fig. 22. These thrusters are currently characterized by low efficiencies. Input power and average thrust are presented in Fig. 23 and Fig. 24 respectively. The input power requirement is several hundreds of kilowatts and the average thrust is a few newtons. Due to low efficiencies, the power to thrust ratios of these devices are rather high, particularly if they are to be operated at higher specific impulses (in excess of $40 \mathrm{kw} / \mathrm{N}$, Fig. 25). Due to insufficient design information about the thrust chamber, MPD thruster system mass could not be determined.

Free Radical Thruster

To obtain free radical thruster characteristics, the molar ratio of $\mathrm{H}_{2}$ and $\mathrm{H}$ in the recombination chamber is varied from $0: 1$ to $10: 1$. It is assumed that 50 percent of the energy released in recombination is available as the kinetic energy of the exhaust beam. Due to lack of 


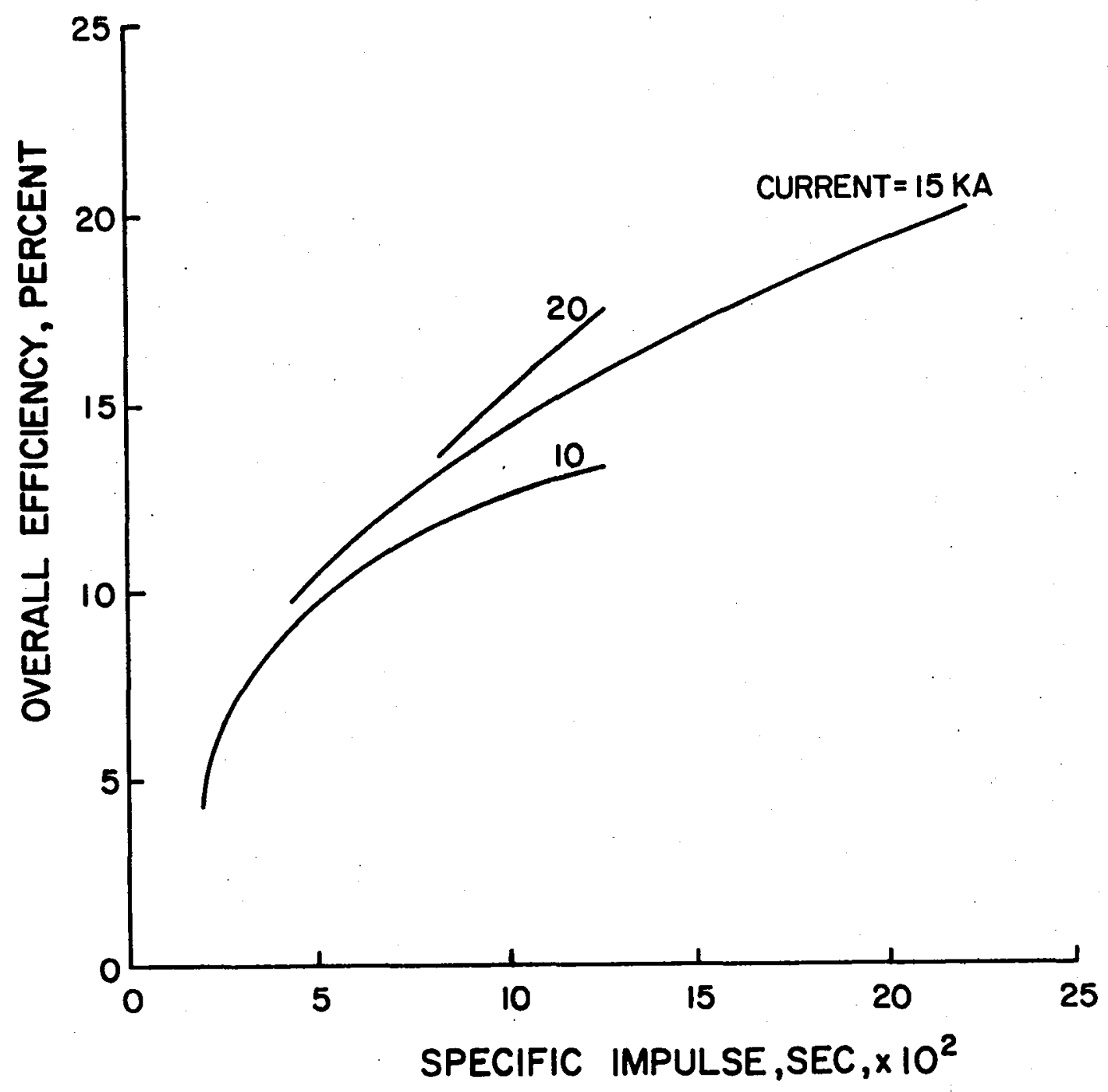

Figure 22. Overall Efficiency of MPD Thruster Versus Specific Impulse for Current Pulses of 10, 15 and $20 \mathrm{KA}$. 


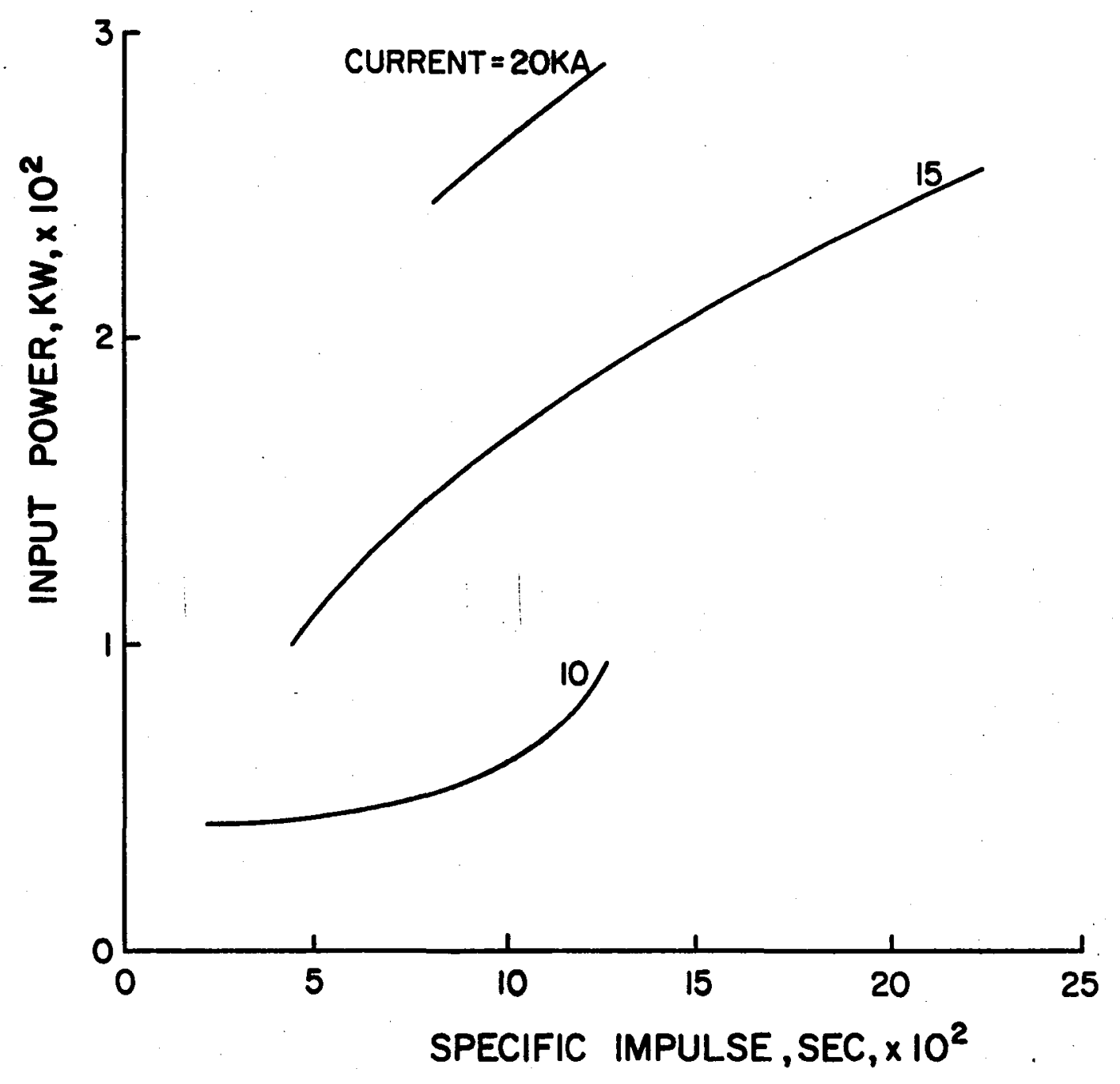

Figure 23. Input Power of MPD Thruster Versus Specific Impulse for Current Pulses of 10,15 and $20 \mathrm{KA}$. 


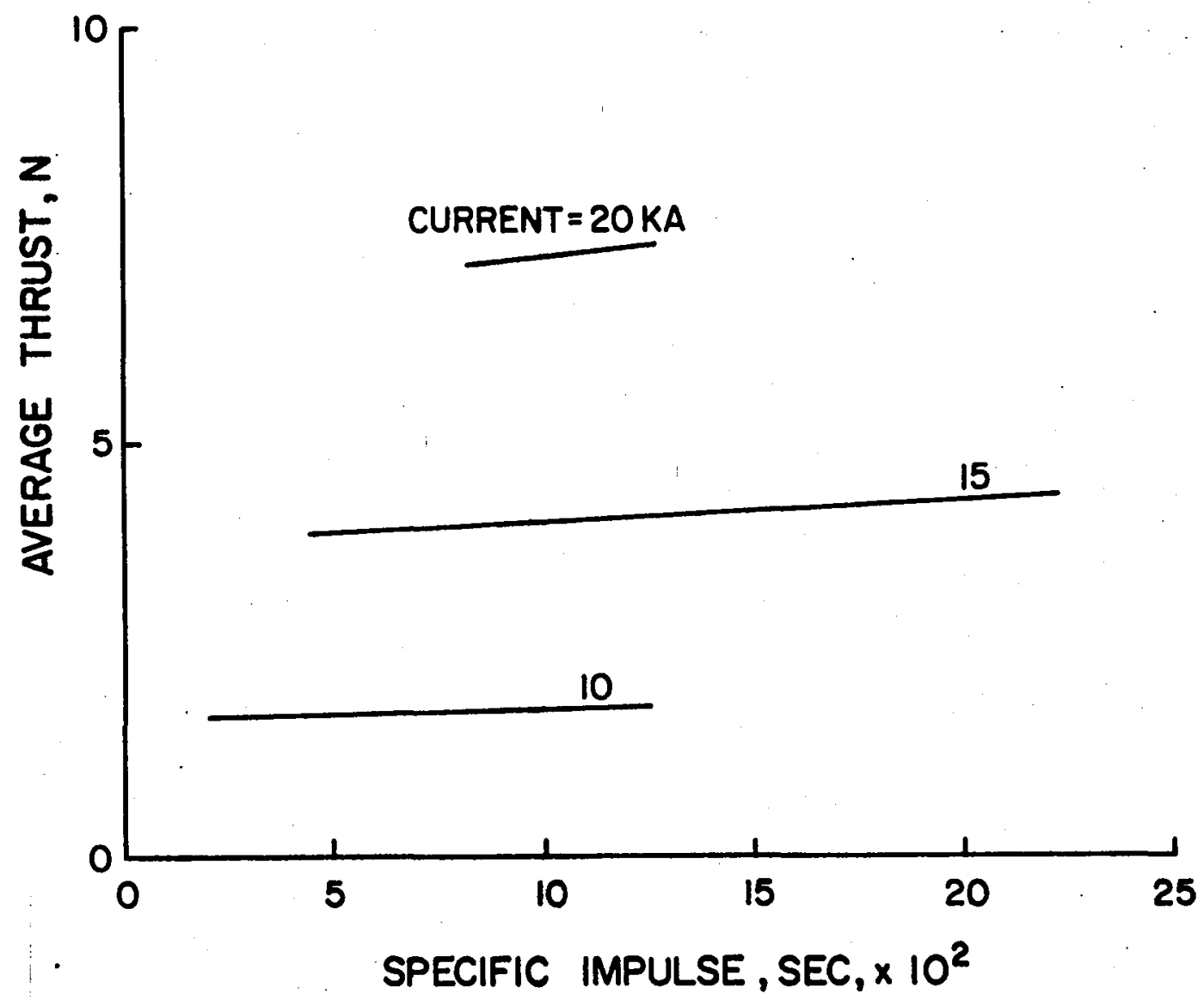

Figure 24. Average Thrust of MPD Thruster Versus Specific Impuise for Current Pulses of 10,15 and $20 \mathrm{KA}$. 


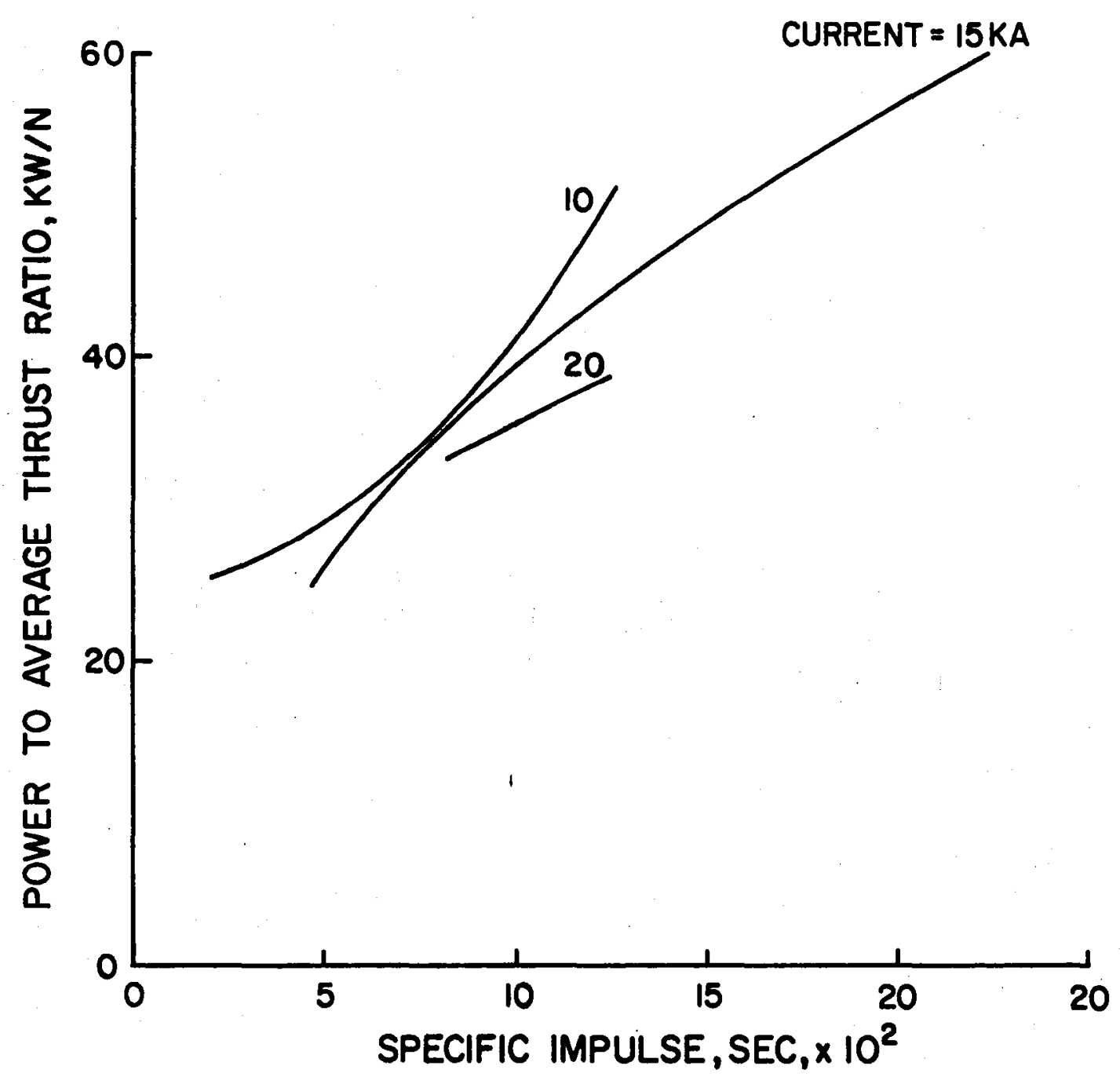

Figure 25. Effect of Specific Impulse on Power to Average Thrust Ratio of MPD Thruster for Current Pulses of 10,15 and 20 KA. 
sufficient experimental or design information about the plasma cavity, we have assumed the microwave energy conversion efficiency to produce the desired $\mathrm{H}_{2}: \mathrm{H}$ molar ratios as 0.3 and 0.6 to reflect two possible designs. The $\mathrm{H}_{2}$ flow rate is assumed to be $1 \mathrm{gm} / \mathrm{sec}$. The relevant equations are listed in Appendix D.

Under the conditions mentioned above, the specific impulse of hydrogen free radical thruster varies from $325 \mathrm{sec}\left(\right.$ for $\mathrm{H}_{2}: \mathrm{H}=10: 1$ ) to $1500 \mathrm{sec}$ (for $\mathrm{H}_{2}: H=0: 1$ ) as shown in Fig. 26. The thrust produced is tens of newtons (Fig. 27) and the input power ranges from tens to hundreds of kilowatts (Fig. 28). The power to thrust ratio is high for low $\mathrm{H}_{2}: \mathrm{H}$ molar ratios (Fig. 29) which implies higher specific impulses. Due to insufficient information about the design of dissociation and recombination chambers, mass of the free radical thruster could not be determined.

Mercury Electron Bombardment Ion Engine

The characteristics of a 50 ' $\mathrm{cm}$ dia mercury electron bombardment ion engine are evaluated for specific impulses ranging from 2000 to $4000 \mathrm{sec}$. For specific impulses of 2000 and $3000 \mathrm{sec}$, the total accelerating voltage is assumed to be 2000 volts which provides ratios of net to total accelerating voltage of 0.25 and 0.56 respectively. For the specific impulse of $4000 \mathrm{sec}$, the total accelerating voltage is assumed to be 2500 volts which provides the ratio of net to total accelerating voltage of 0.79 . The equations defining total power requirement and thrust are provided in Appendix E. The masses of various subsystems and the power dissipated are calculated by following the methodology of Byers. 27 


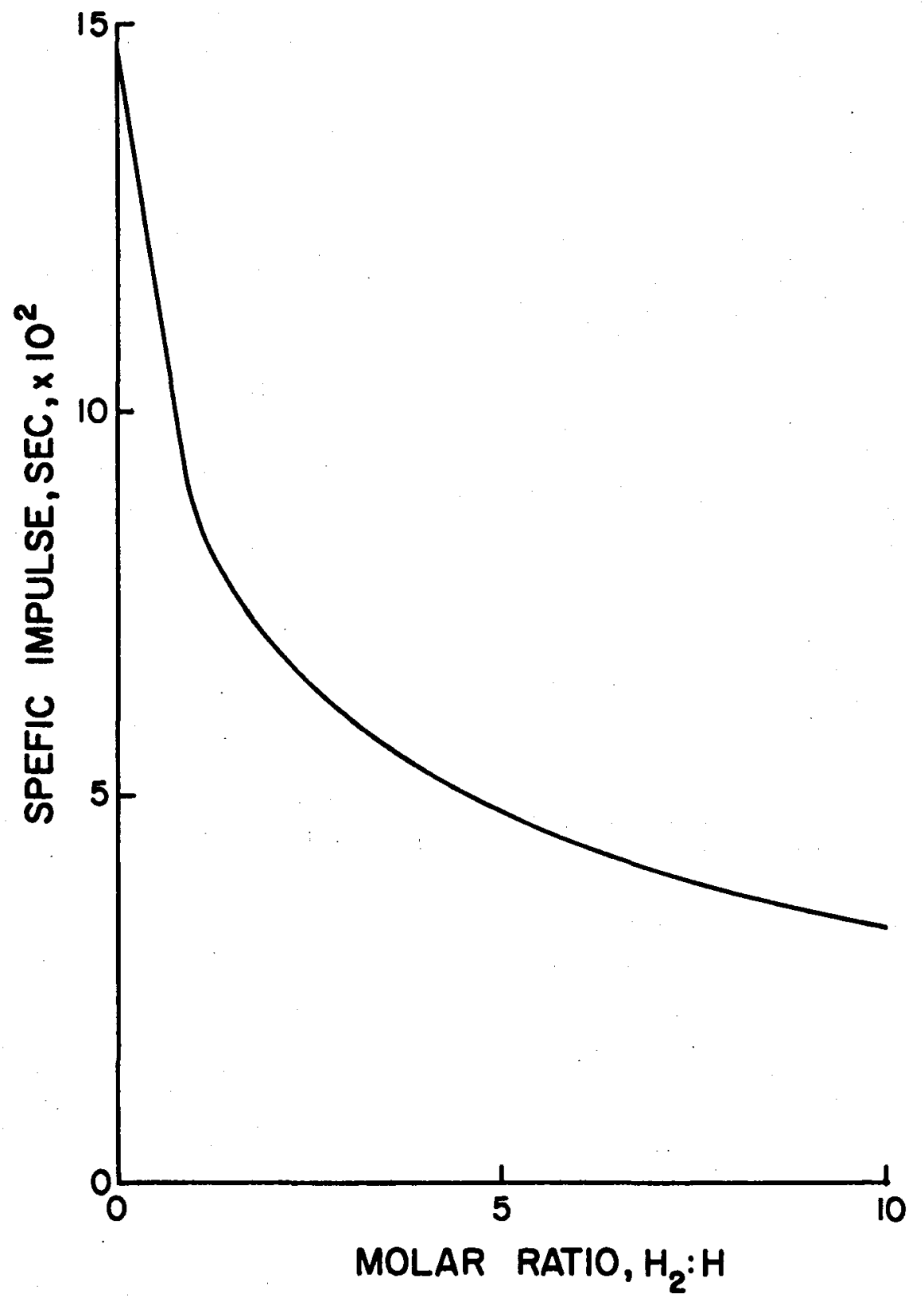

Figure 26. Specific Impulse Versus Molar Ratio of Molecular and Atomic Hydrogen in the Recombination Chamber of Hydrogen Free Radical Thruster. 


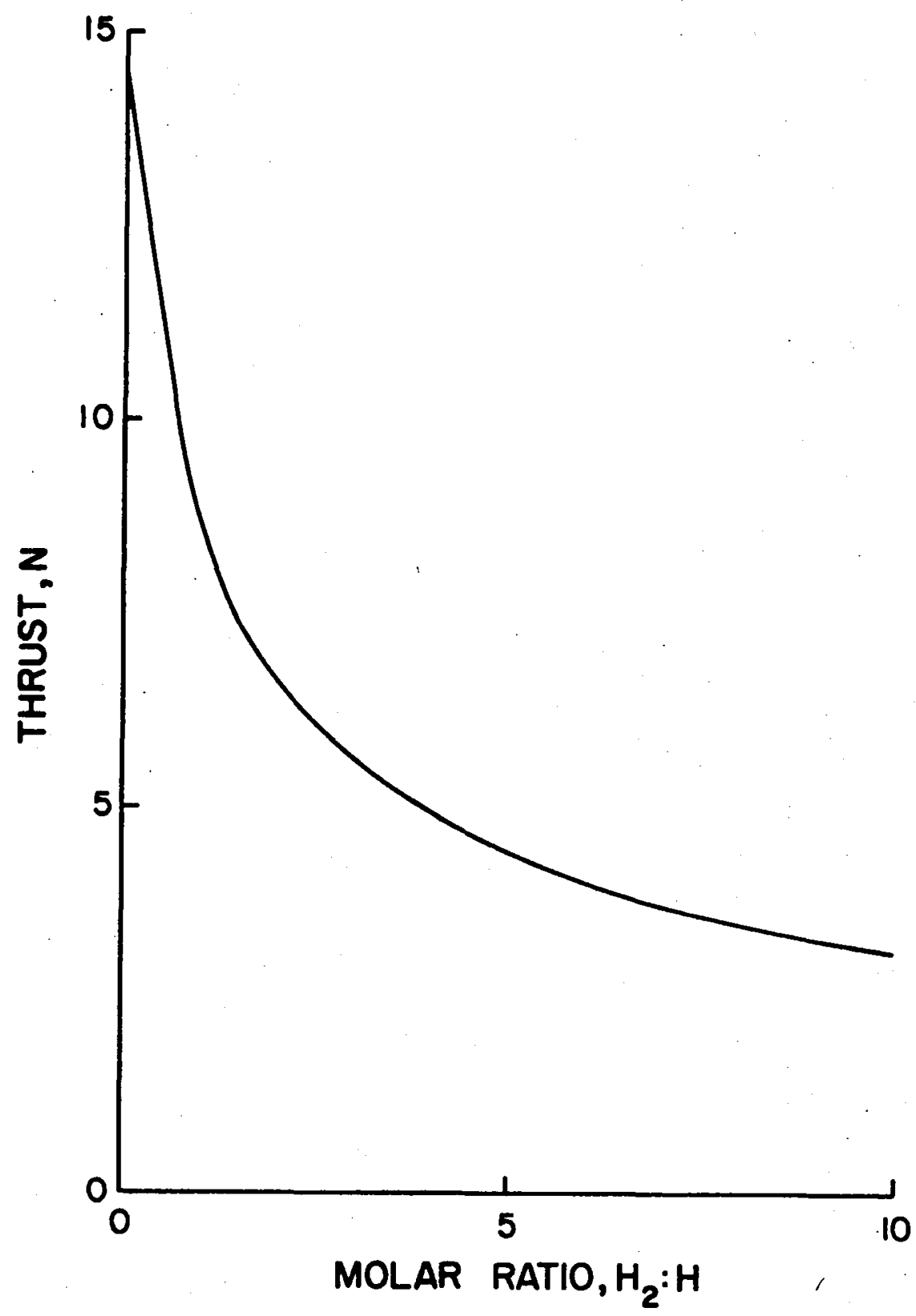

Figure 27. Thrust Versus Molar Ratio of Molecular and Atomic Hydrogen in the Recombination Chamber of Hydrogen Free Radical Thruster. 


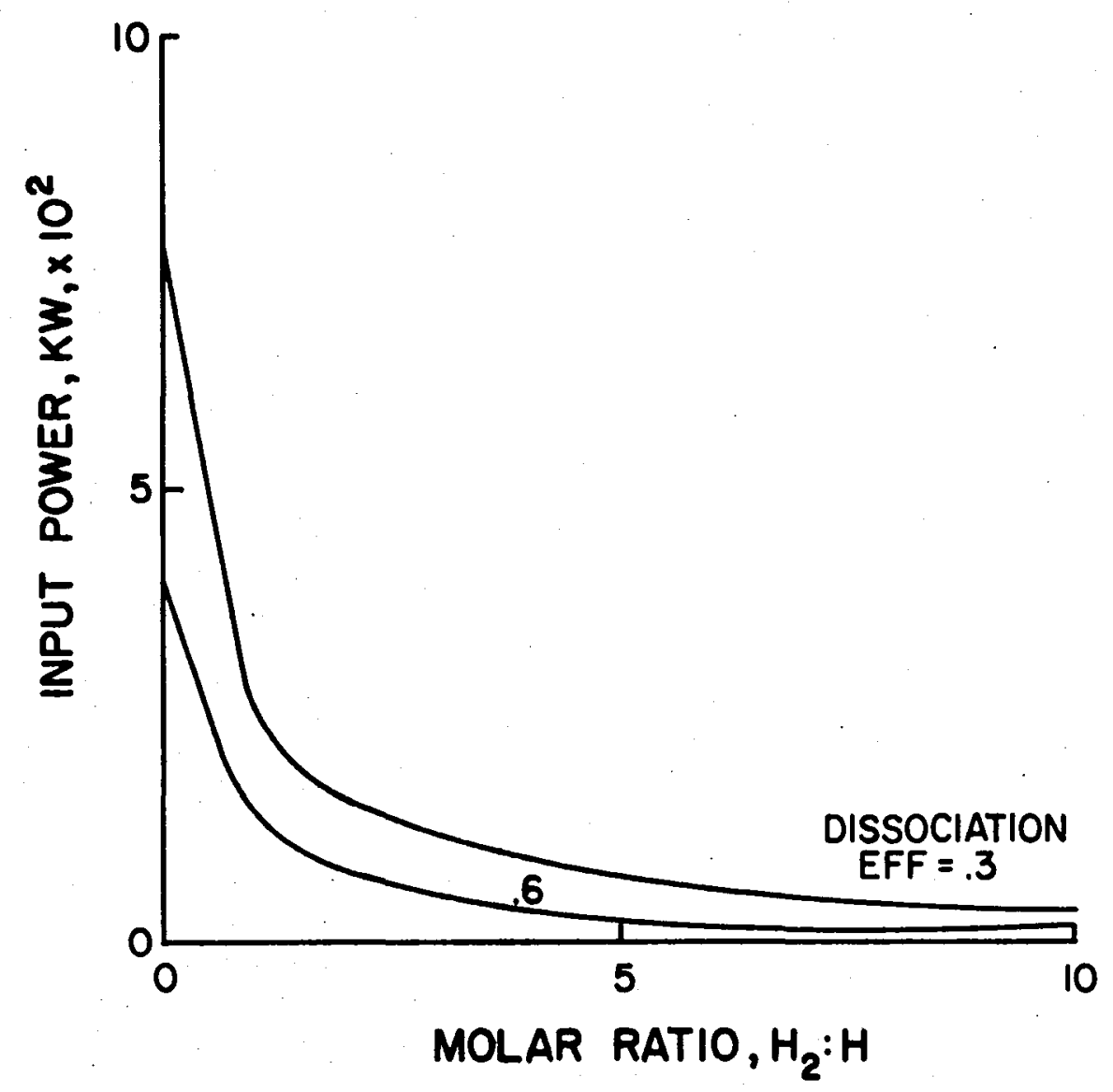

Figure 28. Input Power Versus Molar Ratio of Molecular and Atomic Hydrogen in the Recombination Chamber of Hydrogen Free Radical Thruster. 


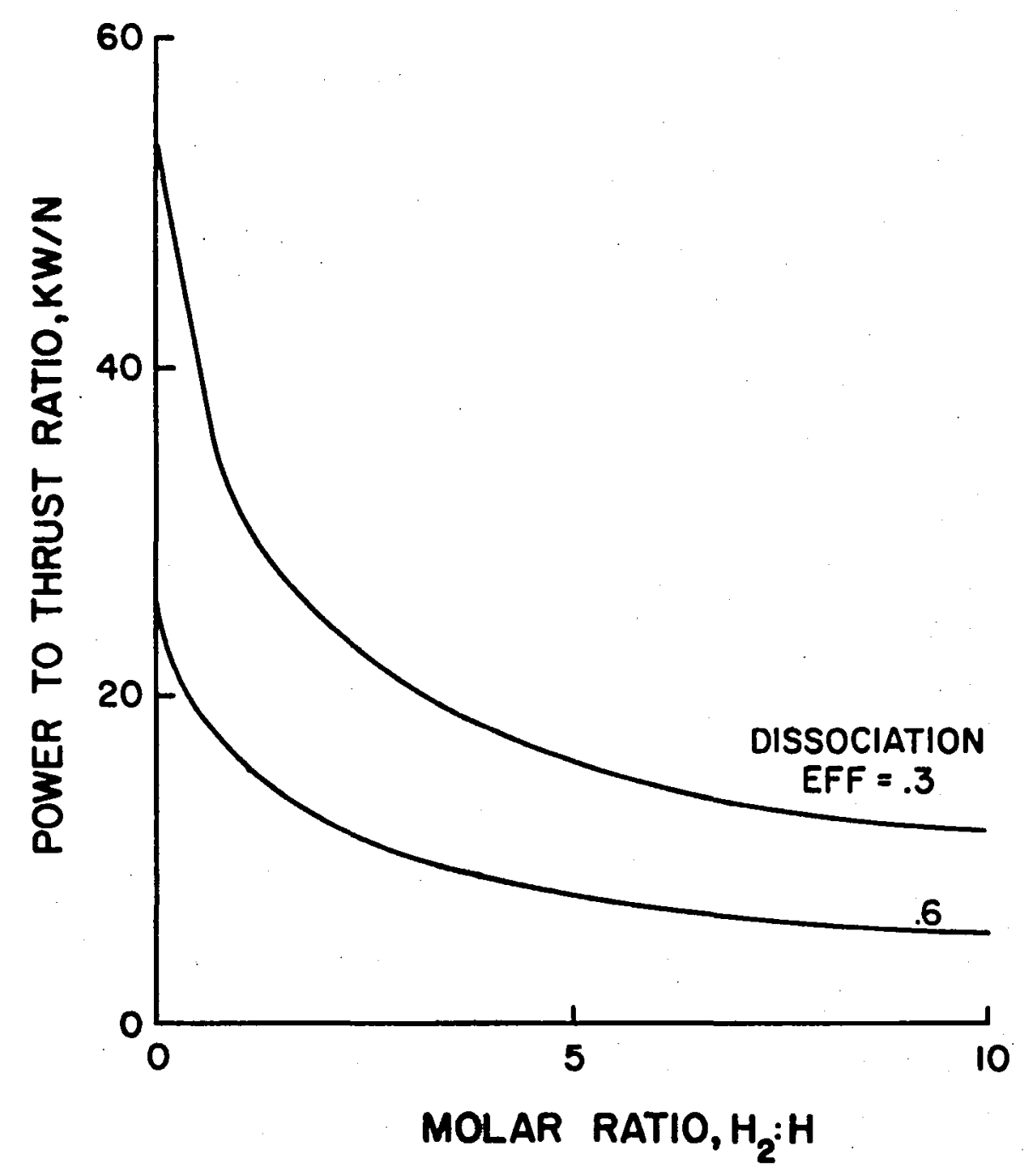

Figure 29. Power to Thrust Ratio Versus Molar Ratio of Molecular and Atomic Hydrogen in the Recombination Chamber of Hydrogen Free Radical Thruster. 
Overall efficiency of the ion engine is presented in Fig. 30 against specific impulse. These thrusters operate at quite high efficiencies, 55 percent to 68 percent for the range of specific impulses concerned. The input power requirement is tens of kilowatts (Fig. 31) and the thrust developed is a few newtons (Fig. 32). Dry system mass is shown in Fig. 33. Figure 34 provides the power to thrust ratio which ranges from 18 to $30 \mathrm{kw} / \mathrm{N}$. Thrust to dry weight ratio remains practically constant at $2 \times 10^{-4}$ (Fig. 35 ). 


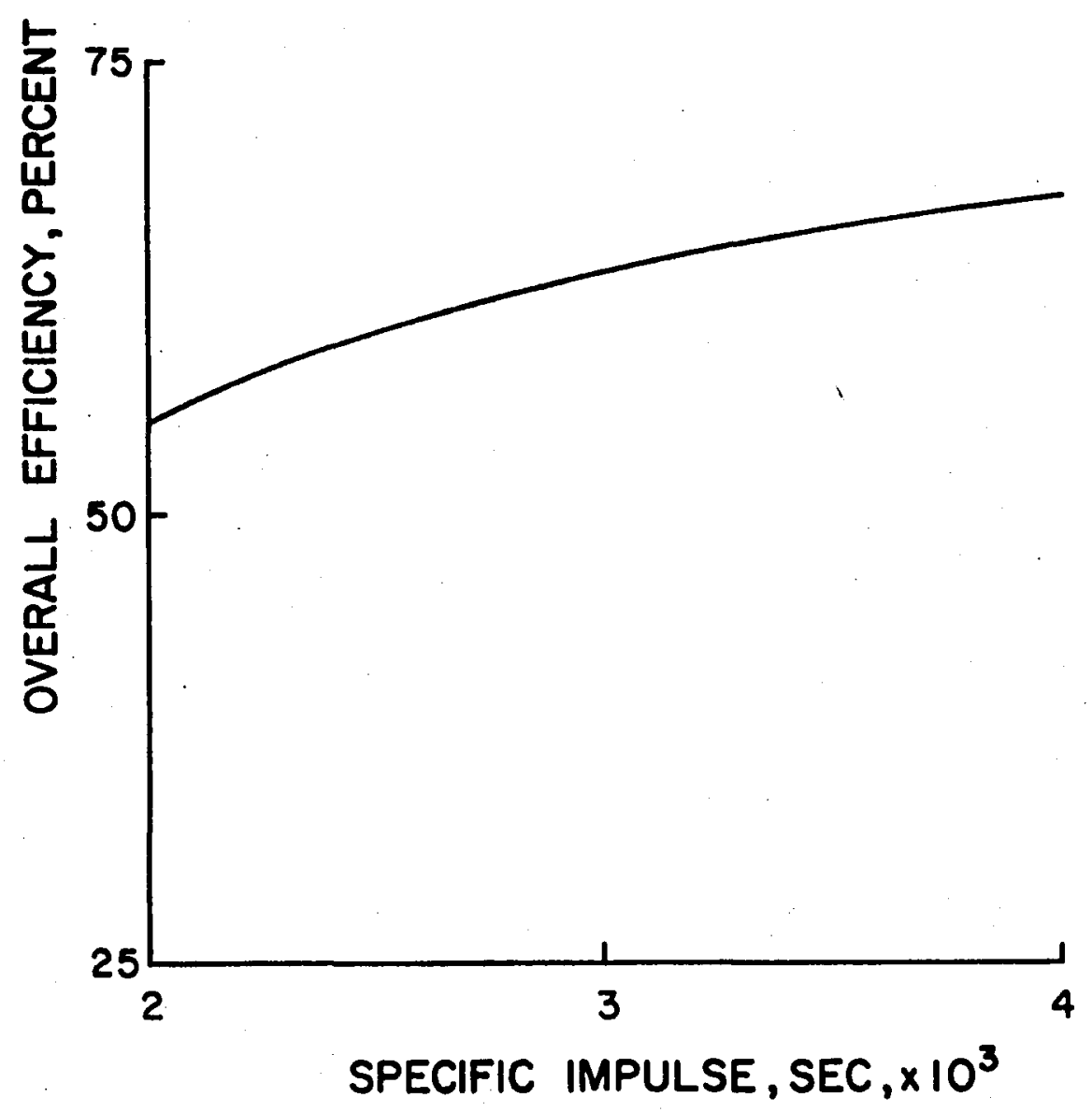

Figure 30. Effect of Specific Impulse on Overall Efficiency of Mercury Ion Engine. 


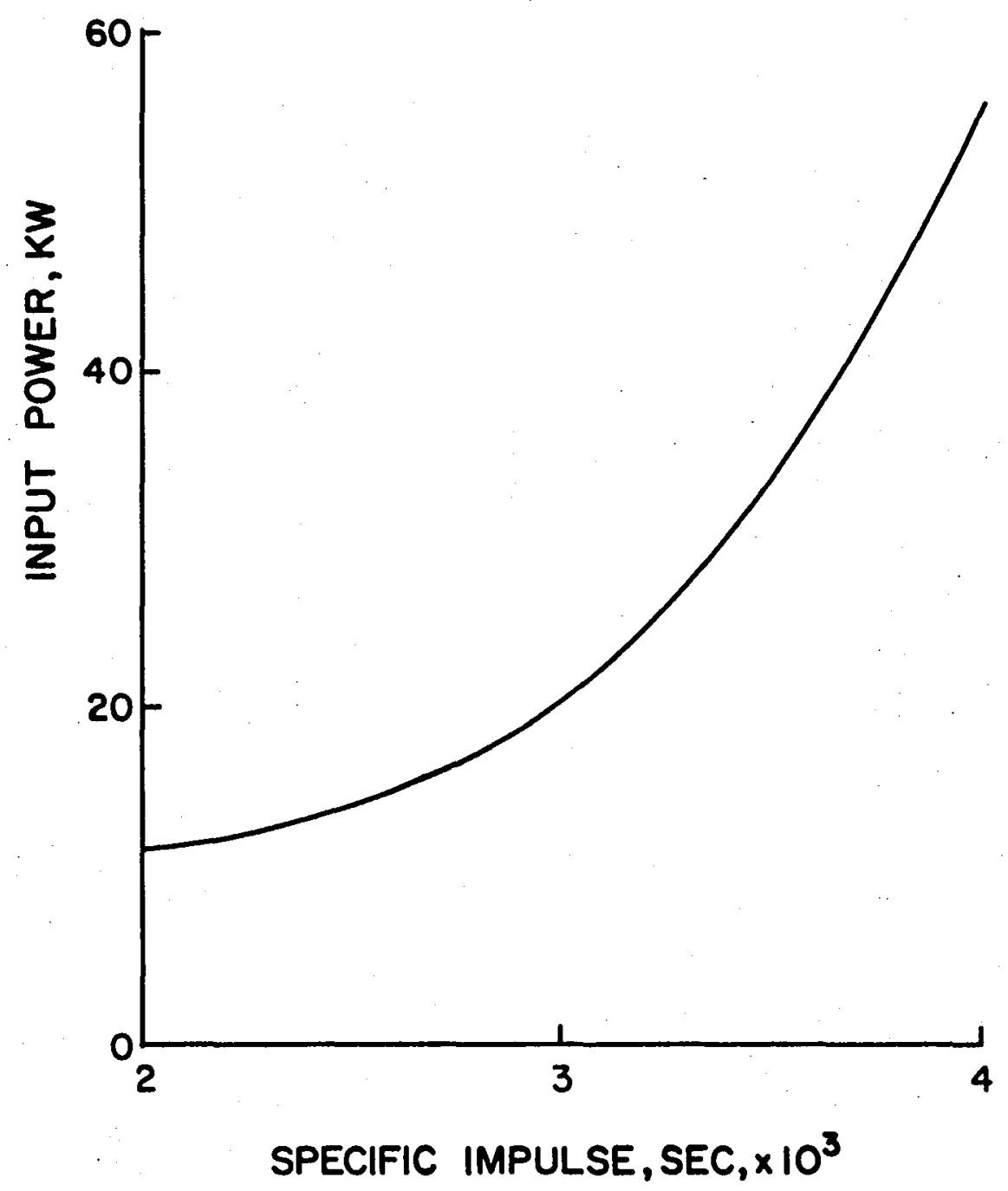

Figure 31. Effect of Specific Impulse on Input Power of Mercury Ion Engine. 


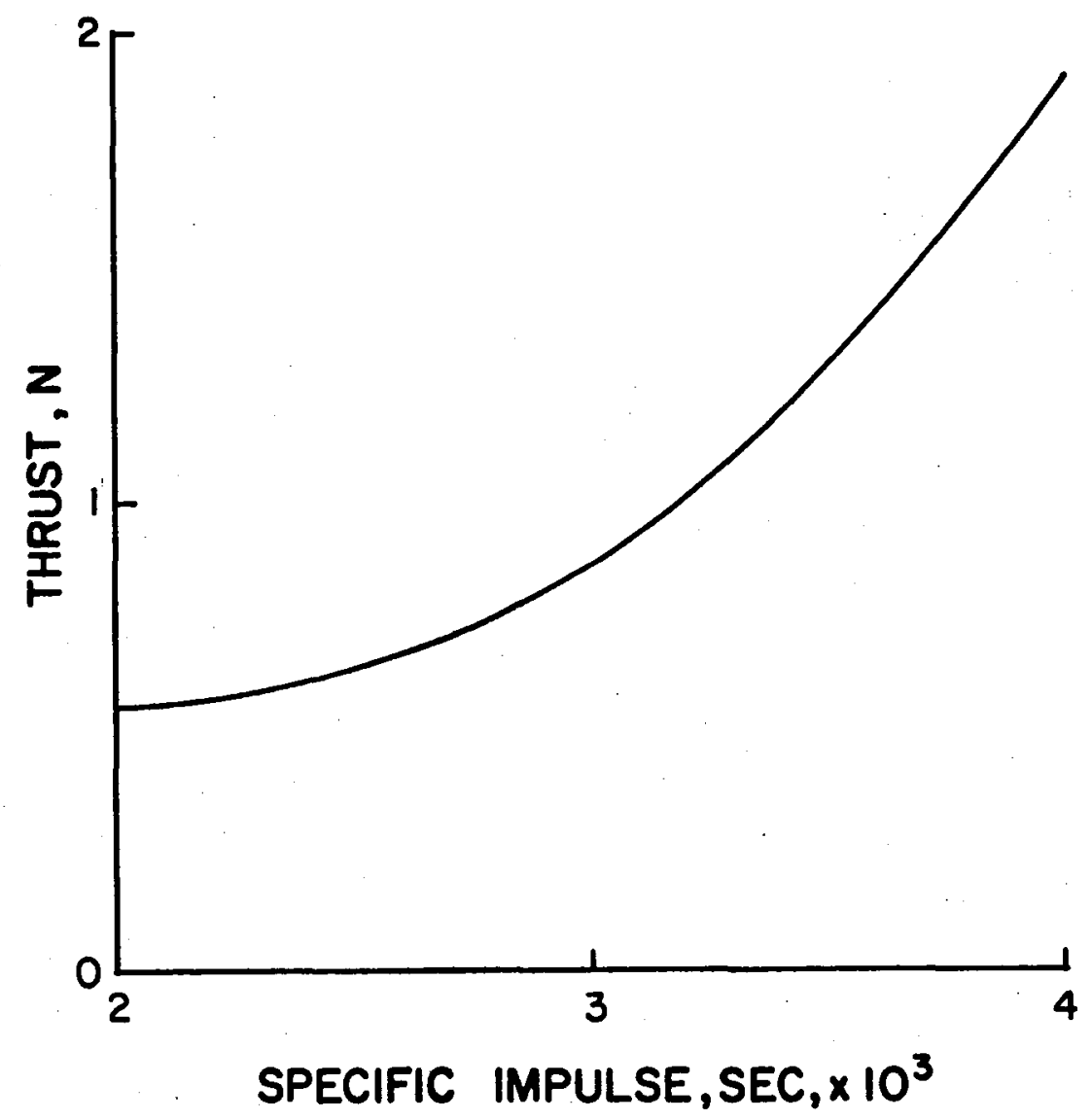

Figure 32. Effect of Specific Impulse on Thrust of Mercury Ion Engine. 


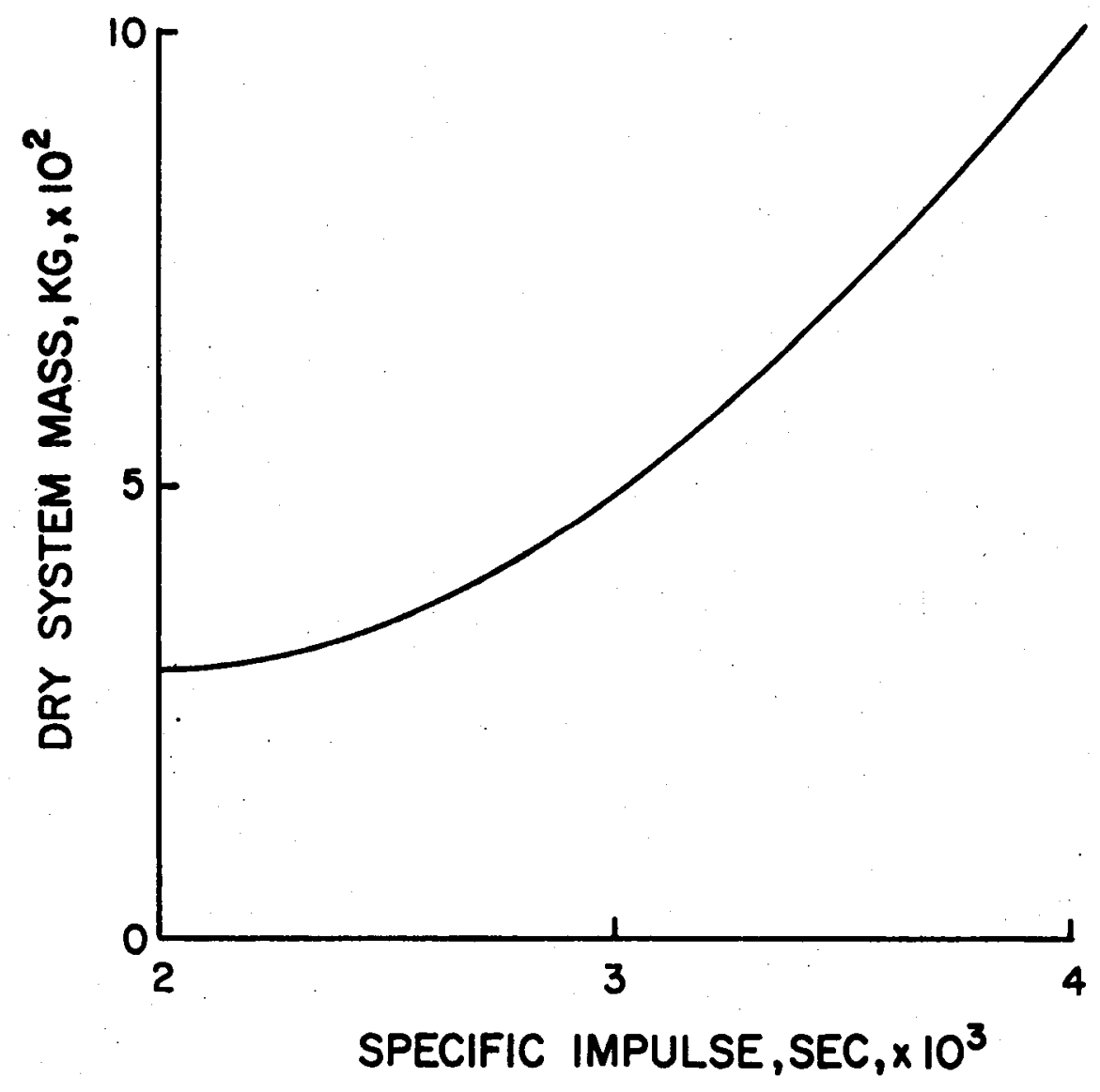

Figure 33. Effect of Specific Impulse on Dry System Mass of Mercury Ion Engine. 


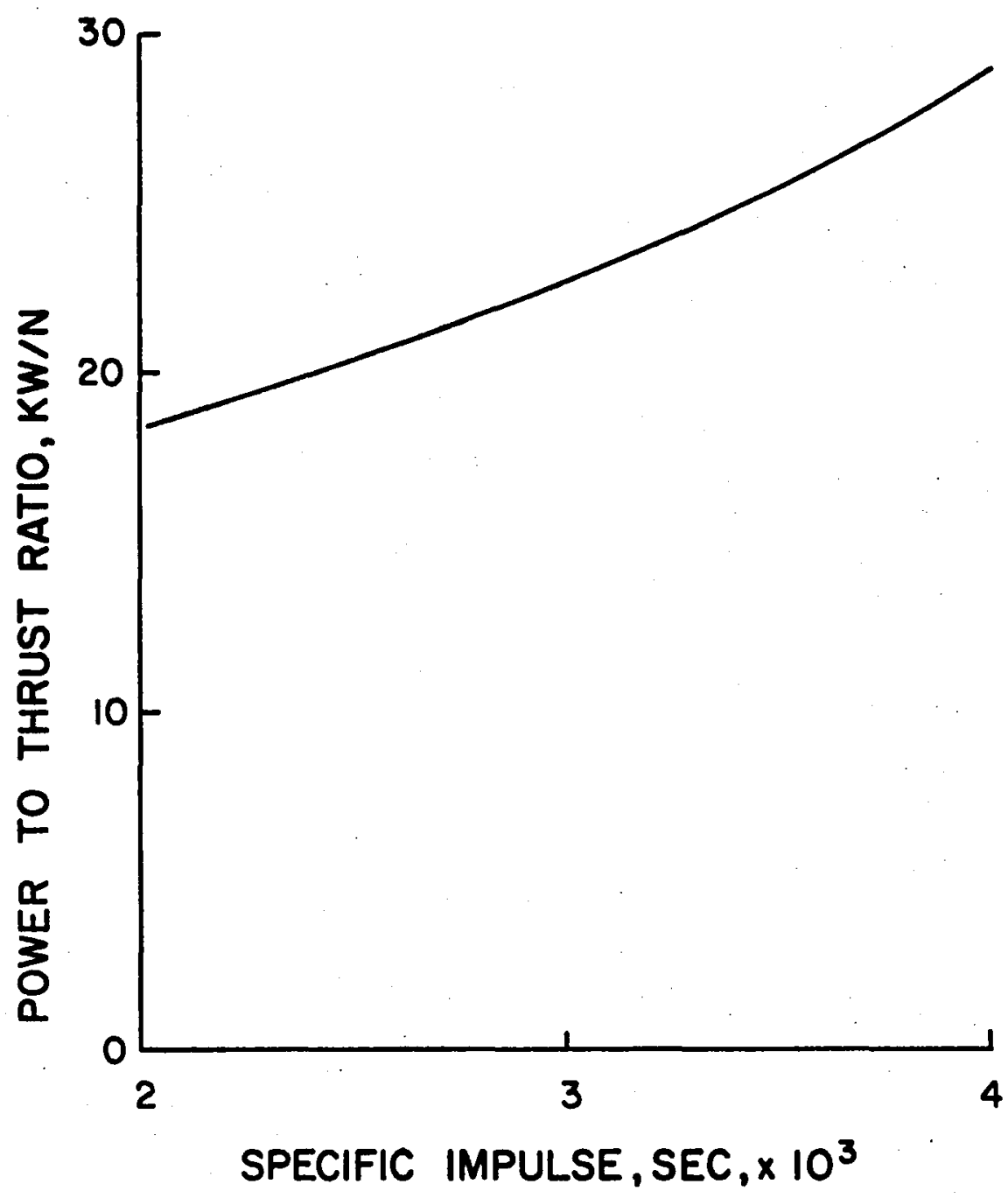

Figure 34. Power to Thrust Ratio of Mercury Ion Engine Versus Specific Impulse. 


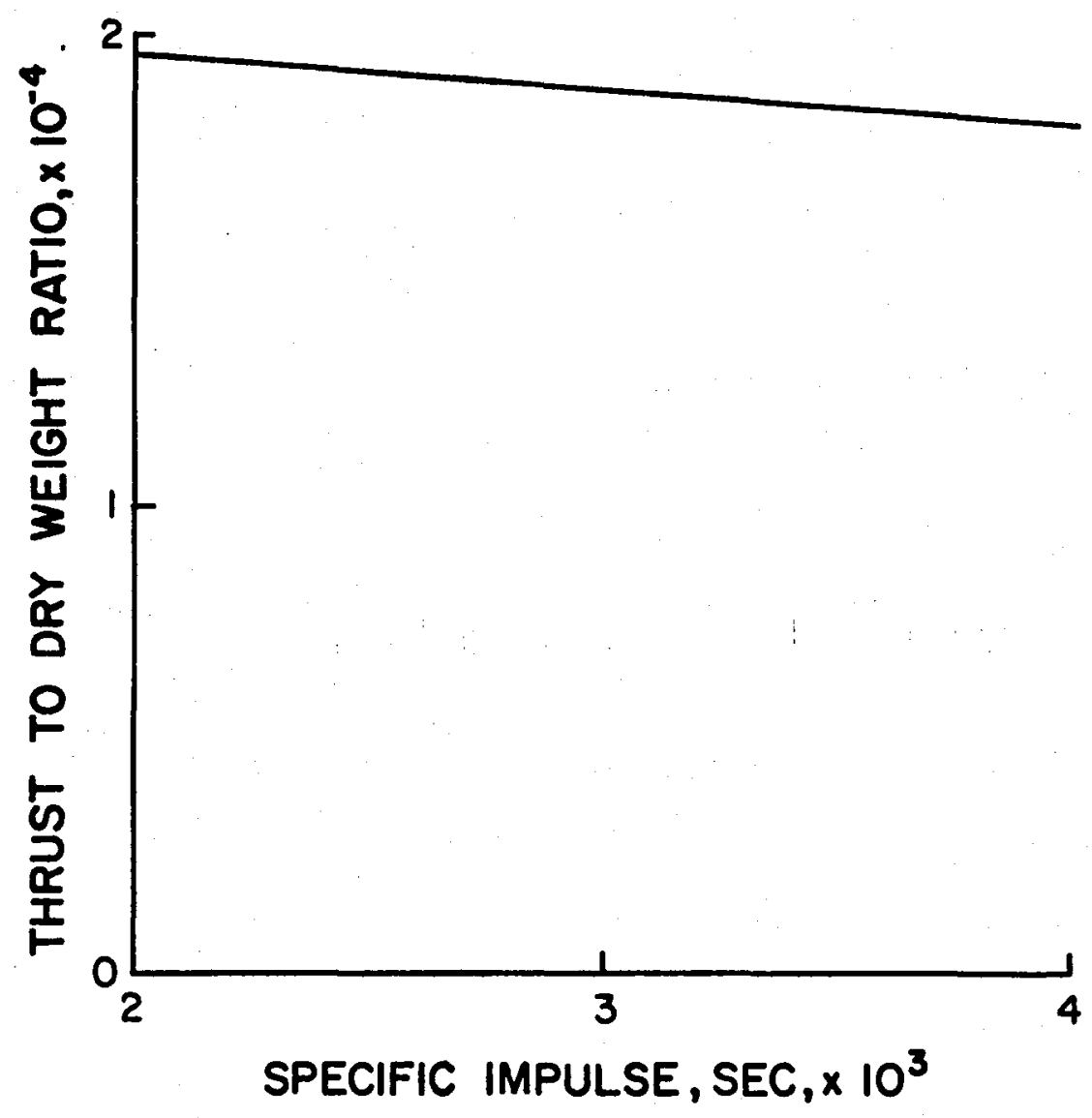

Figure 35. Thrust to Dry Weight Ratio of Mercury Ion Engine Versus Specific Impulse. 


\section{COMPARATIVE EVALUATION}

The five electric propulsion systems are compared on the basis of four parameters; specific impulse, overall efficiency, power to average thrust ratio and average thrust to dry weight ratio. Two of these parameters are most important in characterizing any rocket propulsion system, specific impulse and overall efficiency. The specific impulse signifies how effectively the fuel is being utilized. Overall efficiency has a considerable effect on the total mass of the propulsion system, through power plant and radiator masses, which in turn affect the payload capacity of the spacecraft.

Each type of electric propulsion system can be operated over a certain range of specific impulse. The characteristics of mass drivers have been calculated for specific impulses varying from 1000 to $1500 \mathrm{sec}$, but even at $I_{s p}=1000 \mathrm{sec}$, this type of propulsion system demands a power of several megawatts. Since, the efficiency of rail guns decreases as the specific impulse is increased, rail gun characteristics have been calculated for $I_{s p}=1000 \mathrm{sec}$ to $I_{s p}=2000 \mathrm{sec}$.

Due to their ability to accelerate macroparticles, both mass drivers and rail guns can produce relatively high average thrusts (tens to hundreds of newtons). Hence, the average thrust densities of these two propulsion systems are high, from $10^{5}$ to $10^{6} \mathrm{~N} / \mathrm{m}^{2}$. Thus, mass drivers and rail guns are basically high power, high thrust devices.

From the experimental data of the benchmark MPD thruster before the onset of voltage fluctuations, it can be seen that the maximum specific impulse is $2200 \mathrm{sec}$. In hydrogen free radical thrusters it is expected to stay below $1500 \mathrm{sec}$. Only ion engines can operate well 
beyond this range, from 2000 to $4000 \mathrm{sec}$. All of these thrusters produce low thrusts ( newtons) and require low input power (hundreds of kilowatts). Thrust densities in these devices are several hundred newtons per square meter.

Overall efficiencies of the five electric propulsion systems are shown in Fig. 36 against specific impulse. For mass drivers, overall efficiency is plotted on the basis of a projectile mass of $15 \mathrm{gm}$ whereas for rail guns, it is plotted for a projectile mass of $0.5 \mathrm{gm}$. For MPD thrusters, overall efficiency presented is for a current pulse of $15 \mathrm{KA}$.

Mass drivers are found to have the highest efficiency of all electric propulsion systems. However, these efficiency values may be too optimistic, because for such a small size linear accelerator, the energy losses are expected to be higher than those obtained from the equations provided in Appendix A. Rail guns are observed to have low efficiencies due to large amounts of energy loss in the rails. There is an appreciable amount of power loss associated with the electromagnetic plasma acceleration process which currently makes the MPD devices a low efficiency thruster. Dissociation efficiency of hydrogen molecules in free radical thrusters has been arbitrarily assumed in this study and for a dissociation efficiency of 0.6 , the overall efficiency of free radical thrusters is 27 percent. Ion engines operate at reasonably high efficiencies because electrostatic acceleration of ions is essentially a loss free process.

Power to average thrust ratios are presented in Fig. 37 against specific impulse. Mass drivers are found to have the lowest power to thrust ratio among all electric propulsion systems. Rail guns and MPD 


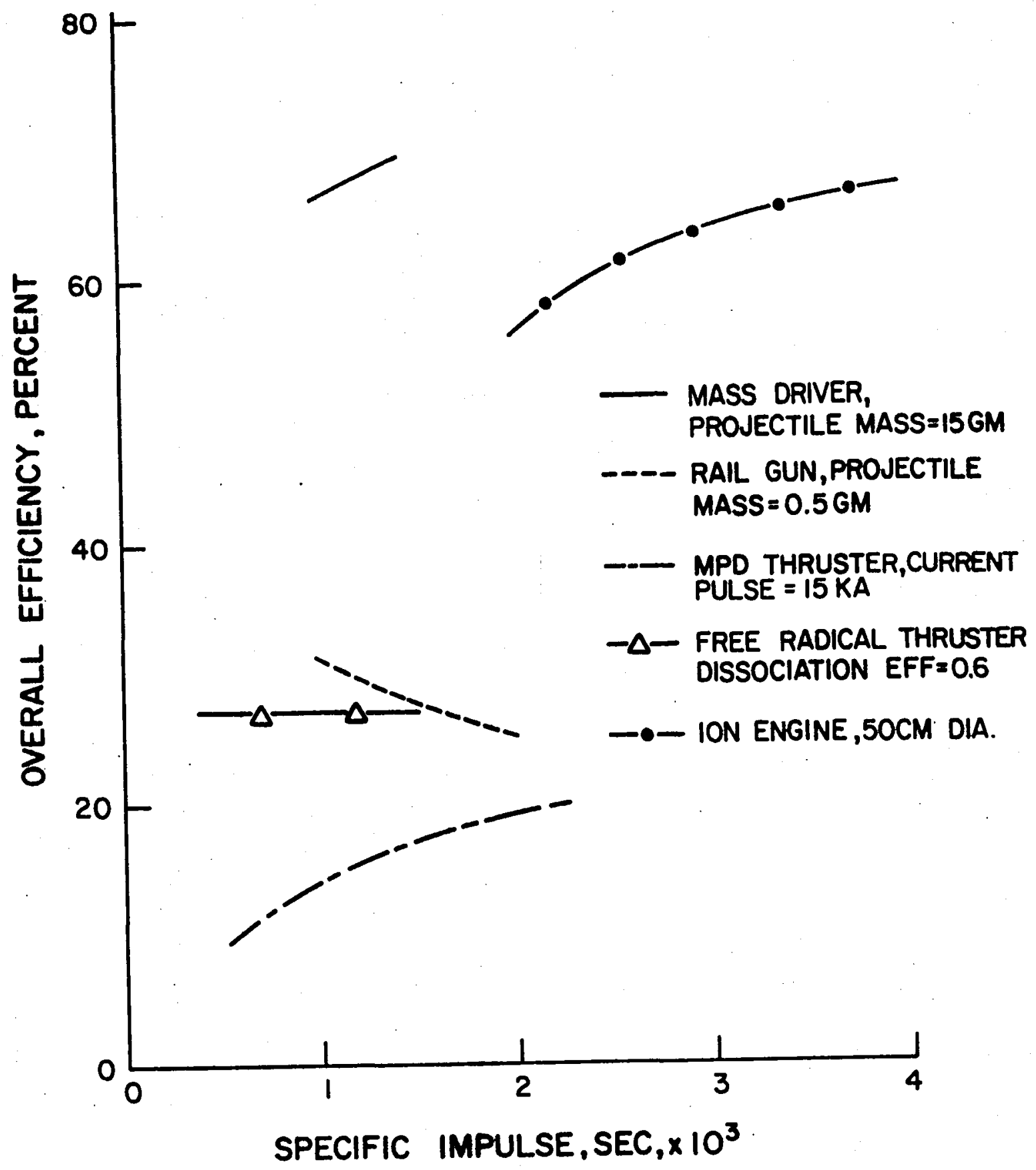

Figure 36. Overall Efficiency of Electric Propulsion Systems Versus Specific Impulse 


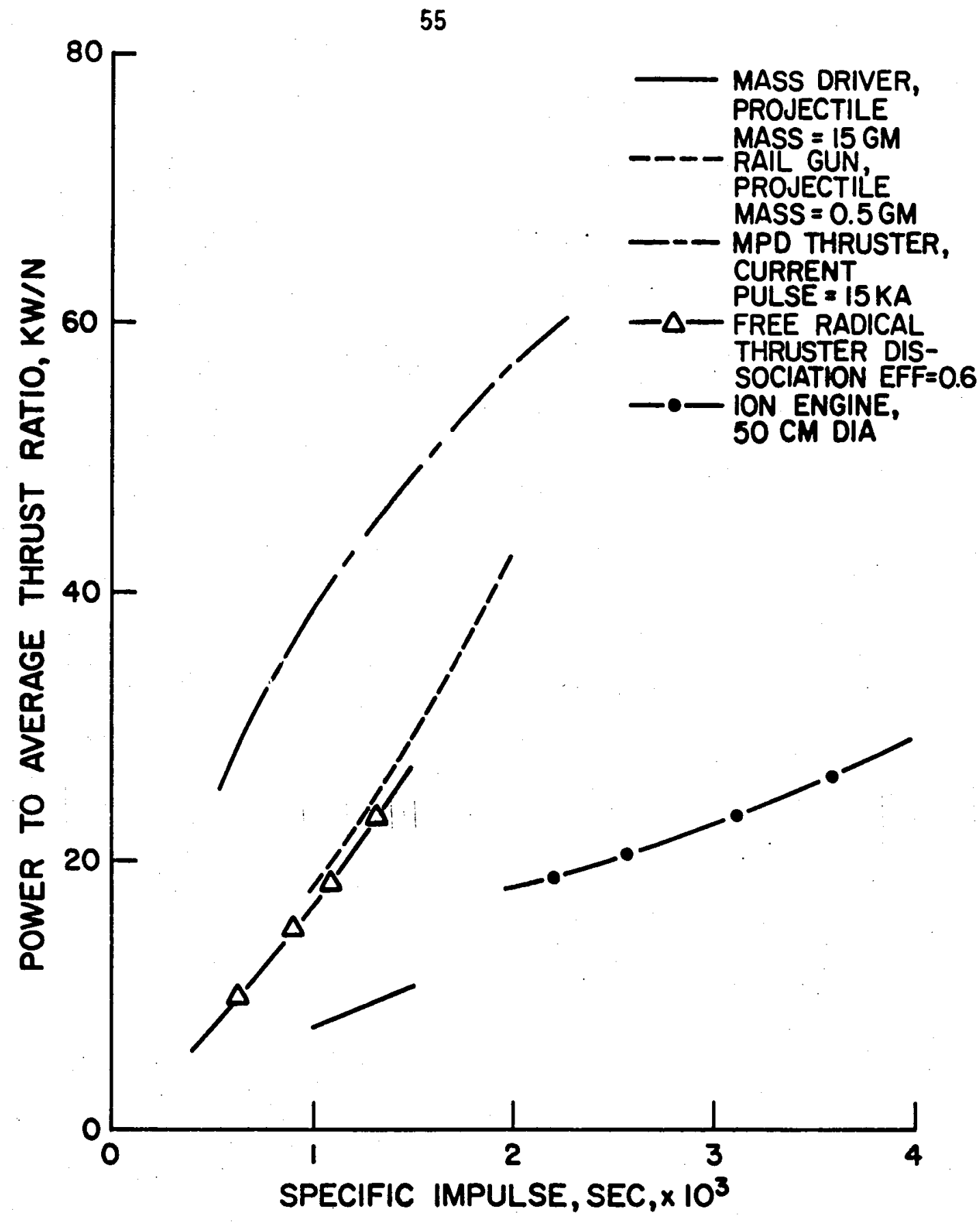

Figure 37. Power to Average Thrust Ratio of Electric Propulsion Systems Versus Specific Impulse 
thrusters have relatively high power to average thrust ratios due to their low efficiencies. Free radical thrusters also have a high power to thrust ratio if a large percentage of $\mathrm{H}_{2}$ can be dissociated in the plasma cavity i.e., if they can be operated at a high specific impulse. Power to thrust ratio of ion engines is low although it operates at considerably higher specific impulses.

Average thrust to dry weight ratio is shown in Fig. 38 for mass drivers, rail guns and ion engines. Mass drivers have the highest thrust to dry weight ratio followed by ion engines and rail guns. Thrust to dry weight ratios of MPD thrusters and free radical thrusters could not be determined due to insufficient design information about these thrusters.

Among the electric propulsion systems evaluated, only the ion engine is flight qualified and ready for a mission. Mass drivers and free radical thrusters are currently in various experimental stages to verify the basic technical concepts. Rail guns and MPD thrusters are in a more advanced development stage having accumulated a large body of experimental data in several laboratories. These electric propulsion systems have to go through an enormous number of development stages, from component development and performance verification to systems engineering studies and reliability testing.

Mass driver characteristics in terms of overa 11. efficiency, power to average thrust ratio and average thrust to dry weight ratio are the best of all electric propulsion systems. Work is currently in progress for improved designs of this type of electromagnetic accelerators. ${ }^{30}$ However, due to limitations of current, acceleration of the projectiles in these systems is restricted to about $10^{3} \mathrm{~g}$ 's. Thus, a very large 


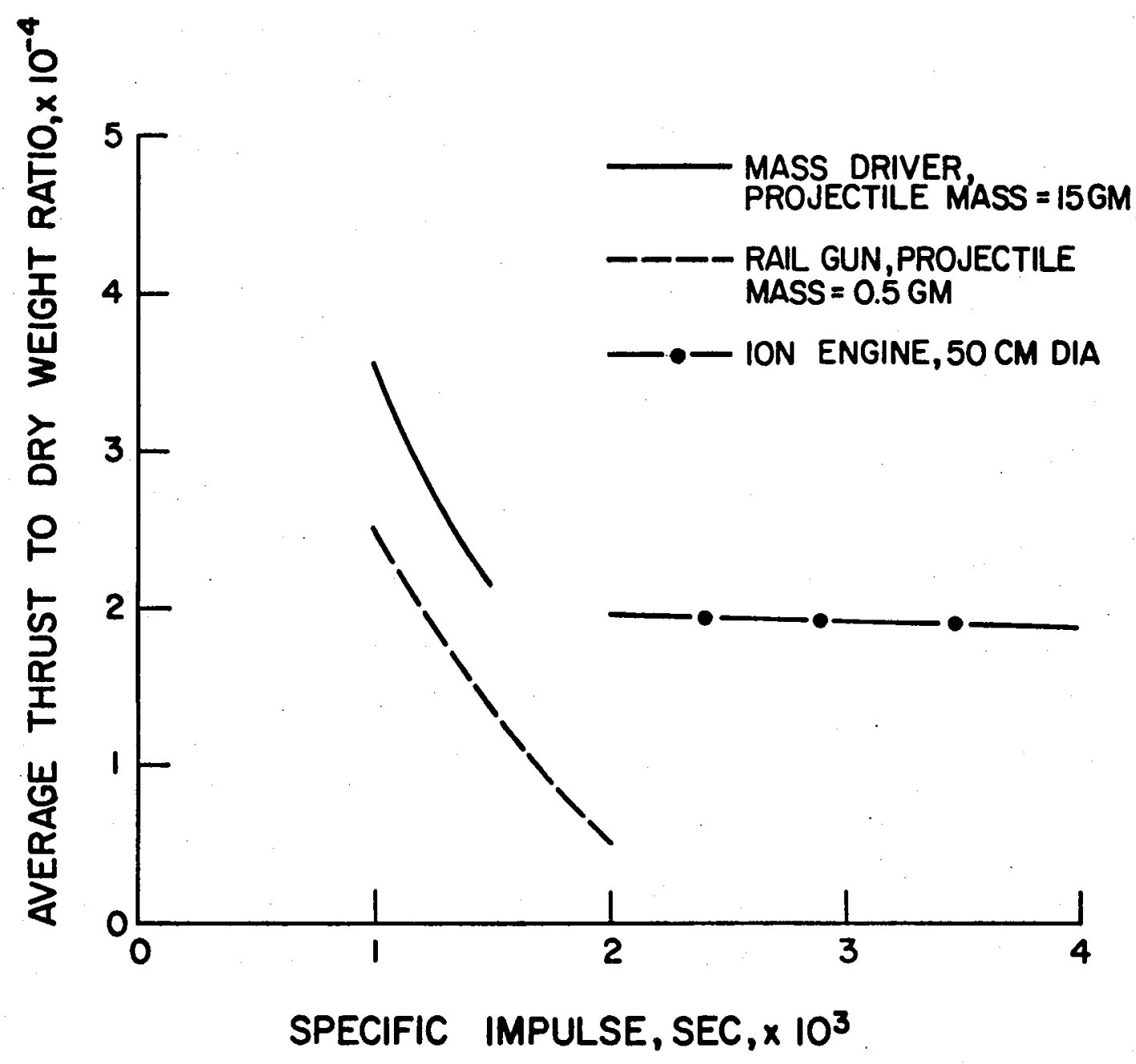

Figure 38. Average Thrust to Dry Weight Ratio of Mass Driver, Rail Gun and Ion Engine Versus Specific Impulse 
length launcher (several kilometers) is required to attain a velocity of the projectile to deliver a specific impulse of at least $1000 \mathrm{sec}$. This limitation in accelerator length is overcome in rail guns where projectiles are capable of achieving very high acceleration $\left(\sim 70^{5} \mathrm{~g} \cdot \mathrm{s}\right)$. Thus, practical length accelerators (tens of meters) can be used to launch reaction masses. However, rail guns are currently characterized by low efficiencies and hence, high power to thrust ratios.

The MPD thrusters also have quite low efficiencies. The power to thrust ratios of these thrusters are consequently high. However, there are indications that the characteristics of the MPD thrusters can be improved as development work continues. By replacing the $10 \mathrm{~cm}$ diameter anode orifice of the benchmark thruster with one of $6 \mathrm{~cm}$ diameter, the specific impulse was increased to $3000 \mathrm{sec}$ and the thruster efficiency was increased to over 30 percent. $^{8}$

The efficiency of dissociation of $\mathrm{H}_{2}$ in a plasma cavity is extremely low. In recent experiments, dissociation efficiencies ranging from 1.5 to 6.0 percent have been observed. ${ }^{25}$ Thus, this type of propulsion system has a long way to go before it be comes viable.

The mercury ion engines offer reasonably high efficiencies. The thrust to dry weight ratio of these devices are comparable to those of mass drivers. The power to thrust ratios of ion engines are somewhat higher than those of mass drivers. Yet these values are low enough despite the fact that ion engines operate at considerably higher specific impulses. Ion engines do not have the drawbacks of mass drivers of a large power requirement or of an exceedingly large length. Although, they produce low thrusts, several of them can be put together in a 
module to provide higher thrust. In view of these, it is concluded that overall, ion engines have somewhat better characteristics as compared to the other electric propulsion systems. 
CONCLUSIONS

of the five electric propulsion systems evaluated, mass driver, rail gun and MPD thruster are impulsive devices whereas free radical thruster and ion engine are continuous thrust devices. Mass driver and rail gun are capable of producing high average thrusts. Consequently, their input power requirements are rather high. In contrast, MPD thruster, free radical thruster and ion engine produce low thrust and hence, have low input power requirements.

Rail gun, MPD thruster and free radical thruster are currently characterized by low efficiencies. Mass drivers are found to be the highest efficiency converters of electrical to kinetic energy. However, even for a small size ( $5 \mathrm{~cm} \mathrm{dia)}$ and a low specific impulse $(1000 \mathrm{sec})$, the required length of a mass driver is several kilometers.

Among the electric propulsion systems studied, only the ion engine can operate at a specific impulse beyond $2000 \mathrm{sec}$. The maximum value of the specific impulse up to which the other electric propulsion systems can be operated is apparently limited to about $2000 \mathrm{sec}$.

Mercury ion engines have demonstrated relatively high efficiencies at low power to thrust ratios while operating at high specific impulses. Given the advanced state of technological development of ion engines combined with their excellent operating characteristics, they have an edge over the other electric propulsion systems. 


\section{REFERENCES}

1. Disher, J. H., "Next Steps in Space Transportation and Operations," Astronautics and Aeronautics, 16, 22 (January 1978).

2. Bekey, I., "Big Comsats for Big Jobs at Low User Cost," Astronautics and Aeronautics, 17, 42 (February 1979).

3. Disher, J. H., "Space Transportation, Satellite Services and Space Platforms," Astronautics and Aeronautics, 17, 43 (April 1979).

4. Kerslake, W. R. and Ignaczak, L. R., "Sert II 1980 Extended Flight Thruster Experiments," NASA Technical Memorandum 81685 (1981).

5. Chilton, F. et al., "Mass-Driver Applications," Prog. in Astronautics, 57, 63 (1977).

6. Barber, J. P., "Electric Rail Gun Application to Space Propulsion," AIAA Paper No. 79-2091 (1979).

7. Hugel, H., "Self-Magnetic Effect in Arcjet Engines," AIAA Journal, $\underline{6}, 1573(1968)$.

8. Burton, R. L. et al., "Thrust and Efficiency of a Self-Field MPD Thruster," AIAA Paper No. 81-0684 (1981).

9. Hawkins, C. E. and Nakanishi, S., "Free Radical Propulsion Concept," NASA Technical Memorandum 81770 (1981).

10. Fearn, D. G., "The Application of Ion Propulsion to the Transportation and Control of Solar Power Satellites," AIAA Paper No. 81-0760 (1981).

11. Chilton, F. et al., "Electromagnetic Mass Drivers," Prog. in Astronautics, 57, 37 (1977).

12. O'Neill, G. K., "Mass Driver Reaction Engine as Shuttle Upper Stage," Space Manufacturing Facilities; Space Colonies 2, Proceedings of the 3rd Princeton/AIAA Conference, ed. Jerry Grey, pp. 109 (1977).

13. Snow, W. R. and $0^{\prime}$ Neill, G. K., "Construction and Testing of the 2.5 m Mass Driver," AIAA Paper No. 79-2095 (1979).

14. Snow, W. R. and Dunbar, R. S., "Mass Driver Reaction Engine Characteristics and Performance in Earth Orbital Transfer Missions," AIAA Paper No. 81-0748 (1981).

15. Marshall, R. A., "The Australian National University Rail Gun Project," Atomic Energy, 1, 18 (1975). 
16. Rashleigh, S. C. and Marsha11, R. A., "Electromagnetic Acceleration of Macroparticles to High Velocities," J. Appl. Phys., 48, 2540 (1978).

17. Bauer, D. P. et al., "Application of Electromagnetic Accelerators to Space Propulsion," Presented at the Conference on Electromagnetic Guns and Launchers," Nov. 4-6, 1980. San Diego, CA.

18. Bauer, D. P. et al., "Electric Rail Gun Propulsion Study," Report AFRPL-TR-81-02 (1981).

19. Bauer, D. P. et al., "The Electric Rail Gun for Space Propulsion," Report NASA-CR-165312 (1981).

20. Hawke, R. S. et al., "Electromagnetic Rail Gun Launchers: Space Propulsion Applications," AIAA Paper No. 81-0751 (1981).

21. Boyle, M. J. et al., "Flowfield Characteristics and Perofrinance Limitations of Quasi-Steady Magnetoplasmadynamic Accelerators," AIAA Journal, 14, 955 (1976).

22. Rudolph, L. K. et al., "Onset Phenomena in Self-Field MPD Arcjets," AIAA Paper No. 78-653 (1978).

23. King, D. Q. et al., "Effect of Thrust Chamber Configuration on MPD Arcjet Performance," AIAA Paper No. 79-2051 (1979).

24. Kuriki, K. et al., "Flight Performance Test of MPD Thruster System," AIAA Paper No. 81-0664 (1981).

25. Chapman, R. et al., "Microwave Plasma Generation of Hydrogen Atoms for Rocket Propulsion," AIAA Paper No. 81-0675 (1981).

26. Etters, R. D. and Flurchik, K., "Atomic Hydrogen Rocket Engine," AIAA Paper No. 81-0677 (1981).

27. Byers, D. C. et al., "Primary Electric Propulsion for Future Space Missions," NASA Technical Memorandum 79141 (1979).

28. Byers, D. C., "Characteristics of Primary Electric Propulsion Systems," NASA Technical Memorandum 79255 (1979).

29. Byers, D. C., "Upper Stages Utilizing Electric Propulsion," NASA Technical Memorandum 81412 (1980).

30. O'Neill, G. K. et al., "High Performance Mass Drivers," AIAA Paper No. 81-0749 (1981).

31. Stewart, P. A. E., "Liquid Hydrogen as a Working Fluid in Advanced Propulsion Systems," British Interplanetary Society Journal, 18, 225 (1961). 
32. Szego, G. C., "Similitudes and Limitations in Trans-Conventional Propulsion Systems," Presented at 9th International Astronautical Congress, Amsterdam, pp. 421 (1958). 
APPENDIX A

Axial Mass Driver

An axially symnetric mass driver with a four-coil carrier is considered in this study. ${ }^{12}$ The nominal diameter of the drive winding is $5 \mathrm{~cm}$. The parameters of the mass driver are listed in Tables 1 and 2 . At a current density of $25,000 \mathrm{anip} / \mathrm{cm}^{2}$ in the superconducting coils of the carrier, total carrier mass is estimated to be $22 \mathrm{gm}$. The axial force, $F_{X}$, on the bucket is found to be $180 \mathrm{~N}$.

The acceleration, $a$, of the carrier is

$$
a=\frac{F_{x}}{22+m}
$$

where $m$ is the reaction mass in $\mathrm{gm}$. For a given specific impulse, I $\mathrm{sp}$, the exhaust velocity, $v_{\max }$, is given by

$$
V_{\max }=9.81 I_{s p}
$$

The length of the accelerator section, $S_{a}$, is

$$
S_{a}=\frac{\left(v_{\max }\right)^{2}}{2 a}
$$

and the length of the decelerator section, $S_{d}$, is

$$
S_{d}=S_{a} \cdot \frac{22}{22+m}
$$

The total length of the mass driver, $S_{\text {tot }}$, is

$$
S_{\text {tot }}=S_{a}+S_{d}
$$


Table 1

Mass Driver Design Parameters

\begin{tabular}{|c|c|c|}
\hline $\mathrm{R}$ & Radius of drive winding & $2.5 \mathrm{~cm}$ \\
\hline$r$ & Radius of driven coil $(0.53 \mathrm{R})$ & $1.33 \mathrm{~cm}$ \\
\hline $1_{p}$ & $\begin{array}{l}\text { Distance between coils carrying in-phase } \\
\text { currents }(2.5 \mathrm{R})\end{array}$ & $6.3 \mathrm{~cm}$ \\
\hline $\mathrm{n}_{2}$ & Number of turns per drive winding & 8 \\
\hline$i_{d}$ & Peak drive current & 7,580 amp-turns \\
\hline$I_{w}$ & Circumference of drive winding & $15.9 \mathrm{~cm}$ \\
\hline$L_{w}$ & Inductance per winding & $0.165 \mu \mathrm{H}$ \\
\hline $\mathrm{n}_{\mathrm{C}}$ & $\begin{array}{l}\text { Number of sine wave excitation cycles undergone } \\
\text { by each drive coil }\end{array}$ & 4 \\
\hline$n_{w}$ & $\begin{array}{l}\text { Number of drive coils simultaneously connected } \\
\text { to each sector capacitor bank }\end{array}$ & 4 \\
\hline$F_{x}$ & Axial force on bucket & $180 \mathrm{~N}$ \\
\hline
\end{tabular}

Table 2

Geometry-Independent Mass Driver Parameters

\begin{tabular}{lll}
\hline$\rho_{R}$ & Resistivity of winding & $2.81 \times 10^{-8} \Omega-\mathrm{m}$ \\
$\rho_{\mathrm{kg}}$ & Density of winding & $2,800 \mathrm{~kg} / \mathrm{m}^{3}$ \\
$\mathrm{~m}_{\mathrm{S}}$ & Specific mass of SCR & $5 \times 10^{-9} \mathrm{~kg} / \mathrm{volt}$-amp \\
$\mathrm{m}_{\mathrm{C}}$ & Specific mass of capacitor & $8 \times 10^{-3} \mathrm{~kg} / \mathrm{Joule}$ \\
$\mathrm{m}_{\mathrm{P}}$ & Specific mass of power plant & $10 \mathrm{~kg} / \mathrm{kw}$ \\
$\mathrm{m}_{\mathrm{R}}$ & Specific mass of radiator & $10 \mathrm{~kg} / \mathrm{kw}$ \\
\hline
\end{tabular}


The total mass of the silicon-controlled rectifiers, $M_{S}$, is given by

$$
M_{s}=8 \pi\left(\frac{i_{d}}{l_{p}}\right)^{2} S_{\text {tot }} V_{\max } L_{w} \frac{m_{S}}{f_{m}}
$$

where $f_{m}$ is the ratio of $\left(V_{\max } / 1_{p}\right)$ to the resonant LC frequency. The total mass of windings and the masses of power supplies and radiators associated with their losses is minimized with respect to the crosssectional area of the winding, $A_{d o}$. The optimum value of $A_{d o}$ is

$$
A_{d o}=\left[\frac{{ }_{C} l_{P} f_{R} f_{m} i_{d}^{2} \rho_{R}\left(m_{P}+m_{R}\right)}{4 v_{\max } \rho_{k g}}\right]^{1 / 2}
$$

and is reached at equal masses for the windings and those of their associated power supplies and radiators. The total mass of winding, $M_{W}$, is

$$
M_{w}=12 S_{\text {tot }}{ }^{1}{ }^{A}{ }_{\text {do }} \rho_{k g} / I_{p}
$$

The total mass of capacitors and feeders and the masses of power supplies and radiators associated with their losses is minimized simultaneously with respect to sector length, $1_{S}$, and feeder conductor crosssectional area, $A_{f o}$. The optimum value of $A_{f o}$ is

$$
A_{f o}=\left[\frac{n_{w}^{3} L^{i}{ }_{d}^{4} m_{C} \rho_{R} f_{R} f_{m}\left(m_{p}+m_{R}\right)}{128 n_{2}^{2} \rho_{k g}^{2} v_{\max }}\right]^{1 / 3}
$$


and is reached at equal masses for the three components. The total mass of each of the three components, $M_{C}$, when minimized is

$$
M_{c}=12 A_{\text {fo }} S_{\text {tot }}{ }^{\rho} k g
$$

The average thrust, $T$, and the average kinetic power output, $P_{0}$, in the exhaust beam are given by,

$$
T=f_{R} m V_{\max }
$$

and

$$
P_{0}=\frac{1}{2} f_{R} m v_{\text {max }}^{2}
$$

The average power radiated is calculated by dividing the total power and radiator masses by the sum of power plant and radiator specific masses. The average power input is the sum of average kinetic power output and the average power radiated. In the absence of design data, the mass of the power conditioning system is assumed to be $5 \mathrm{~kg}$ per kilowatt of input power and the bucket return passageway mass is assumed to be $2 \mathrm{~kg}$ per kilowatt of input power. The efficiency of the power conditioning system is taken to be 0.9 . The overall efficiency is calculated by dividing the average power output in the exhaust beam by the power output of the power plant. 
APPENDIX B

Rail Gun Thruster

The correlations developed by Bauer et al. are used to calculate the characteristics of rail gun thrusters. ${ }^{19}$ For a given projectile mass, $m$, and exhaust velocity, $v$, the efficiency of the accelerator, $n_{a}$, is approximated by

$$
n_{a}=1.367 m^{0.104} v^{-0.299}
$$

where $\mathrm{m}$ is in $\mathrm{kg}$ and $v$ is in $\mathrm{km} / \mathrm{sec}$. The projectiles are assumed to be made of a composite of resin and graphite fibers having a density of $2,200 \mathrm{~kg} / \mathrm{m}^{3}$ to withstand extremely high accelerating stresses. It is further assumed that the projectile thickness is half the bore width, $H$. For a square bore rail gun, $H$ is then

$$
H=\left(\frac{2 m}{2200}\right)^{1 / 3}
$$

The optimum length of the rail gun, $x$, is correlated to the bore width and exhaust velocity by,

$$
x=45.6 \mathrm{Hv}^{2}
$$

where $H$ is in meters. The current, $I$, required to accelerate the projectiles to the required exhaust velocity is

$$
I=\left(\frac{2 m a}{L}\right)^{1 / 2}
$$


where $a$ is acceleration of the projectile and $L$ is the inductance gradient of the rails and assumed to be $0.4 \times 10^{-6}$ Henry/meter. The acceleration, $a$, is

$$
a=\frac{v^{2}}{2 x}
$$

The average thrust, $T$, and the average power output in the exhaust beam, $P_{0}$, are given by,

$$
T=f_{R} m v
$$

and

$$
P_{0}=f_{R}\left(\frac{m v^{2}}{2}\right)
$$

where $f_{R}$ represents number of projectiles launched per second. The average power input, $P_{\text {in }}$, is

$$
p_{\text {in }}=\frac{p_{0}}{r_{a} \eta_{p s}}
$$

where $\eta_{p s}$ is the efficiency of the power conditioning system and assumed to be 0.9 . The overall efficiency of the rail gun, $n$, is

$$
n=n_{a}^{n} \text { ps }
$$

The mass of the accelerator $M_{a}$, is correlated by

$$
M_{a}=1.17 \times 10^{2} m v^{2}+2.99 \times 10^{-6} m^{5 / 6}(v \times 1000)^{5 / 2}
$$


where $m$ is in $\mathrm{kg}, v$ is in $\mathrm{km} / \mathrm{sec}$ and $M_{a}$ is in $\mathrm{kg}$. The power conditioning system mass is assumed to be $5 \mathrm{~kg}$ per kilowatt of input power and the pellet handling system mass is assumed to be $1 \mathrm{~kg}$ per kilowatt of input power. The radiator and power plant specific masses are taken to be $10 \mathrm{~kg} / \mathrm{kw}$ each. 


\section{APPENDIX C}

MPD Thruster

The empirical relationships developed for the benchmark argon MPD thruster at Princeton University are used here. ${ }^{8}$ The thrust, T, is correlated by

$$
T=b J^{2}
$$

where $J$ is the current pulse in amperes and $b$ is a proportionality constant given by

$$
b=1 \times 10^{-7}\left[\ln \left(\frac{0.011 \mathrm{~J}^{2}}{\dot{\mathrm{m}}}+5.63\right)\right]
$$

In equation $2, \mathrm{~J}$ is in kiloamperes and $\dot{\mathrm{m}}$ is the argon mass flow rate in $\mathrm{gm} / \mathrm{sec}$. The specific impulse, $I_{s p}$, and the thruster efficiency, $\eta_{t}$, are given by,

$$
I_{s p}=\frac{T}{\dot{m} g}
$$

and

$$
n_{t}=\frac{T^{2}}{2 \dot{m} J V}
$$

where $V$ is the terminal voltage. The thrust, $T$, obtained from equation 1 is impulsive thrust. In this study, we have assumed that the thrust remains steady for a period $\tau=1 \mathrm{msec}$ and the cycle time $T_{c}$ is $10 \mathrm{msec}$. The average thrust, $T_{a v}$, is then 


$$
T_{a v}=T \cdot \frac{\tau}{T_{c}}
$$

The average power output in the exhaust beam, $P_{0}$, is

$$
P_{0}=T_{a v} \cdot \frac{v}{2}
$$

where $v$ is the velocity of exhaust gases. The average power input, $P_{\text {in }}$, is

$$
P_{\text {in }}=\frac{p_{o}}{n_{t} n_{p s}}
$$

where $n_{p s}$ is the efficiency of the power conditioning system and assumed to be 0.9 . The overall efficiency of the MPD thruster, $\eta$, is

$$
n=n_{t} n_{p s}
$$


APPENDIX D

Free Radical Thruster

For the hydrogen free radical thruster, the amount of energy. released due to $100 \%$ dissociation and recombination is $51.21 \mathrm{kcal}$ per gm of gas flow. ${ }^{31}$ However, if only a fraction of the $\mathrm{H}_{2}$ gas flow is dissociated, then the energy released due to recombination of all of the atomic hydrogen will be less than $51.21 \mathrm{kcal}$ per gm of gas flow. Table 1 lists the energy released, $\Delta H$, from several free radical molar compositions, $\mathrm{H}_{2}: \mathrm{H}$, assuming $100 \%$ efficiency in recombination.

All of the energy released due to recombination of free radicals can not be converted into the kinetic energy of the ejected matter. A large portion of the energy of the exhaust gases leaves the nozzle as residual enthalpy. In this study, we have assumed that $50 \%$ of the energy input into the combustion chamber is available for conversion into

\section{Table 1}

Hydrogen Free Radical Thruster Parameters

\begin{tabular}{cccc}
\hline $\begin{array}{c}\text { Free radical } \\
\text { molar composition } \\
\left(\mathrm{H}_{2: H)}(\mathrm{H})\right.\end{array}$ & $\begin{array}{c}\text { Energy release, } \Delta H \\
(\text { kcal per gm of } \\
\text { gas flow) }\end{array}$ & $\begin{array}{c}\text { Specific Imputse } \\
\text { I sp }_{(\mathrm{sec})}\end{array}$ & $\begin{array}{c}\text { Conversion } \\
\alpha\end{array}$ \\
\hline $0: 1$ & 51.21 & 1493 & 1.00 \\
$1: 1$ & 16.98 & 860 & .33 \\
$2: 1$ & 10.18 & 665 & .20 \\
$5: 1$ & 4.62 & 448 & .09 \\
$10: 1$ & 2.42 & 325 & .05 \\
\hline
\end{tabular}


kinetic energy. Under these conditions, the specific impulse, $I_{s p}$, of the free radical thruster is given by ${ }^{32}$

$$
I_{s p}=208(\Delta H)^{1 / 2}
$$

where $\Delta H$ is the energy available from 100\% recombination of the free radicals generated per gm of gas flow. The specific impulses of atomic hydrogen thrusters for several free radical molar compositions are also listed in Table 1. The velocity of exhaust gas, $v$, the thrust, $T$, and the power output in the exhaust beam, $P_{0}$, are given by

$$
\begin{aligned}
& v=I_{s p} g \\
& T=\dot{\mathrm{m}} \mathrm{v}
\end{aligned}
$$

and

$$
P_{0}=\frac{T V}{2}
$$

where $\dot{\mathrm{m}}$ is the gas flow rate.

The fraction $\alpha$ of $\mathrm{H}_{2}$ molar gas flow converted to atomic hydrogen in the dissociation chamber to get the desired free radical molar composition, $\beta: 1$, can be calculated as follows. For 1 mole of $\mathrm{H}_{2}$ flow into the dissociation chamber, $2 \alpha$ mole of $\mathrm{H}$ is created and $(1-\alpha)$ mole of $\mathrm{H}_{2}$ remains in the mixture. The total number of moles in the mixture is $1+\alpha$ and the $\mathrm{H}$ mole fraction is $2 \alpha /(1+\alpha)$. Then

$$
\frac{2 \alpha}{1+\alpha}=\frac{1}{\beta+1}
$$

or,

$$
\alpha=\frac{1}{2(\beta+0.5)}
$$


Conversion values of $\alpha$ for several free radical molar compositions is provided in Table 1.

The power, $P$, needed to dissociate a fraction $\alpha$ of $\mathrm{H}_{2}$ flow rates of $\dot{M} \mathrm{~mole} / \mathrm{sec}$ is

$$
P=\frac{C \alpha \dot{M}}{n_{d}}
$$

In equation $6, \mathrm{C}$ is the power required to dissociate a flow of $1 \mathrm{~mole} / \mathrm{sec}$ of $\mathrm{H}_{2}$ to $\mathrm{H}$ and $\mathrm{n}_{\mathrm{d}}$ is the efficiency of dissociation of hydrogen molecules by microwave energy. In the absence of adequate information about the design of the dissociation chamber, we have assumed two values of $\eta_{d}$, 0.3 and 0.6 , to reflect two possible values of efficiency of the dissociation process. We have further assumed a power conditioning system efficiency of 0.9 . The calculations have been performed by assuming a $\mathrm{H}_{2}$ mass flow rate of $1 \mathrm{gm} / \mathrm{sec}$. 


\section{APPENDIX E}

Mercury Electron Bombardment Ion Thruster

The performance of ion thrusters is limited by the maximum ion current density and the allowable range of the ratio, $R$, of net to total accelerating voltages, $V_{B} / V_{T}$, over which a thruster may be operated. This ratio. can vary from 0.2 to 0.9 . The total accelerating voltage on close spaced accelerating grids is limited to about 3000 volts.

For mercury ion thrusters, the specific impulse, $I_{s p}$, the total power required, $\mathrm{P}_{\mathrm{T}}$, and the thrust, $\mathrm{T}$, are given by, ${ }^{27}$

$$
\begin{aligned}
I_{S p} & =90.3 V_{B}^{0.5} \\
P_{T} & =2.57 \times 10^{-9} A\left(\frac{V_{B}}{R}\right)^{2.25}\left(V_{B}+150\right) \\
T & =4.9 \times 10^{-9} A \frac{V_{B}^{2.75}}{R^{2.25}}
\end{aligned}
$$

where $A$ is the cross sectional area of the accelerator grid. We have assumed the thruster diameter to be $50 \mathrm{~cm}$ which is a modest extrapolation of the state-of-art technology.

The mass of the propellant tank is assumed to be $50 \mathrm{~kg}$ in all cases. For analysis of power management and control system, the conventional dc configuration is chosen. The masses of various subsystems and the power dissipation were calculated by following the methodology of Byers. ${ }^{28}$ 
DISTRIBUTION LIST

Copies

National Aeronautics and Space Administration Washington, DC 20546

Attn: RS/Mr. Dell Williams, III

RTS-6/Mr. Wayne Hudson

RTS-6/Mr. Jerome Mullin

$\mathrm{MT} / \mathrm{Mr}$. Ivan Bekey

National Aeronautics and Space Administration

Lewis Research Center

21000 Brookpark Road

Cleveland, $\mathrm{OH} 44135$

Attn: Research Support Procurement Section

Mr. Steve Szabo, MS 501-11

Technology Utilization Office, MS 3-19

Report Control office, MS 5-5

Library, MS 60-3

Mr. N. Musial, MS 500-113

Dr. M. Goldstein, Chief Scientist, MS 5-3

Mr. F. Terdan, MS 501-7

Mr. D. Byers, MS 501-7

Mr. W. Kerslake, MS 501-7

Mr. H. Allen, MS 7-3

National Aeronautics and Space Administration

Lyndon B. Johnson Space Center

Houston, TX 77058

Attn: Mr. Hu Davis

National Aeronautics and Space Administration

Marshall Space Flight Center

Huntsville, AL 35812

Attn: $M r$. Jerry $P$. Hethcoate

Mr. John Harlow

Mr. Robert Bechte]

Research and Technology Division

Wright-Patterson AFB, OH 45433

Attn: (ADTN) Mr. Everett Bailey

NASA Scientific and Technical

Information Facility

P.0. Box 8757

Baltimore, MD 21240

Attn: Accessioning Dept. 
Case Western Reserve University

10900 Euclid Avenue

Cleveland, $0 \mathrm{H} 44106$

Attn: Dr. Eli Reshotko

DST 1

Ministry of Defence

Metropole Building

Northumberland Avenue

London, WC2 N5BL ENGLAND

Attn: Dr. D. G. Fearn

United Kingdom Atomic Energy Authority

Culham Laboratory

Abingdon, Berkshire

ENGLAND

Attn: Dr. P. J. Harbour

Dr. M. F. A. Harison

National Aeronautics and Space Administration

Goddard Space Flight Center

Greenbe 1t, MD 20771

Attn: Mr. W. Isley, Code 734

Mr. A. A. Vetman

Dr. David H. Suddeth

COMSAT Laboratories

P.0. Box 115

Clarksburg, MD 20734

Attn: Mr. B. Free

Mr. 0. Revesz

Comsat Corporation

950 L'Enfant Plaza, SW

Washington, DC 20024

Attn: Mr. Sidney 0. Metzger

Rocket Propulsion Laboratory

Edwards AFB, CA 93523

Attn: LKDA/Mr. Tom Waddell

LKDH/Dr. Robert Vondra

DFVLR--Institut fur Plasmadynamik

Technische Universitat Stuttgart

7 Stuttgart-Vaihingen

Allmandstr 124

West Germany

Attn: Dr. G. Krulle 
Copies

Giessen University

Ist Institute of Physics

Giessen, West Germany

Attn: Professor H. W. Loeb

Jet Propulsion Laboratory

4800 0ak Grove Drive

Pasadena, California 91102

Attn: Dr. Kenneth Atkins

Technical Library

Mr. Eugene Pawlik

$\mathrm{Mr}$. James Graf

Mr. Dennis Fitzgerald

Dr. Graeme Aston

Electro-0ptical Systems, Inc.

300 North Halstead

Pasadena, Cal ifornia 91107

Attn: Dr. R. Worlock

Mr. E. James

Mr. W. Ramsey

TRW Inc.

TRW Systems

One Space Park

Redondo Beach, California 90278

Attn: Dr. M. Huberman

Mr. Sid Zafran

National Aeronautics and Space Administration Ames Research Center Moffett Field, California 94035

Attn: Technical Library

National Aeronautics and Space Administration Langley Research Center

Langley Field Station

Hampton, Virginia 23365

Attn: Technical Library

Mr. B. Z. Henry

Hughes Research Laboratories

3011 Malibu Canyon Road

Malibu, California 90265

Attn: Mr. J. H. Molitor

Dr. R. L. Poeschel

Dr. Jay Hyman

Dr. J. R. Beattie

Dr. W. S. Williamson

Dr. H. J. King 
Princeton University

Princeton, NJ 08540

Attn: Dean R. G. Jahn

Dr. K. E. Clark

Boeing Aerospace Co.

P.0. Box 3999

Seattle, Washington 98124

Attn: Mr. Donald Grim, M.S. 8K31

Mr. Russell Dod

Lockheed Missiles and Space Co.

Sunnyvale, California 94088

Attn: Dr. William L. Owens

Propulsion Systems, Dept. 62-13

Fairchild Republic Co.

Farmingdale, New York 11735

Attn: Dr. Domenic J. Palumbo

Electrotechnical Laboratory

1-1-4, Umezono, Sakura-Mura,

Ni ihari-Gun

Ibaraki, Japan

Attn: Dr. Katsuya Nakayama

Sandia Laboratories

Mai1 Code 4537

A1buquerque, NM 87115

Attn: Mr. Ralph R. Peters

Ion Tech, Inc.

P.0. Box 1388

1807 E. Mulberry

Fort Collins, Colorado 80522

Attn: Dr. Gerald C. Isaacson

EG \& G Idaho

P.0. Box 1625

Idaho Falls, Idaho 83401

Attn: Dr. G. R. Longhurst, TSA-104

The Aerospace Corporation

P.0. Box 95085

Los Angeles, CA 90045

Attn: Dr. B. A. Haatunion

Mr. A. H. Silva 
$\underline{\text { Copies }}$

Michigan State University

East Lansing, MI 48824

Attn: Dr. J. Asmussen

Dr. M. C. Hawley

General Dynamics

Kearney Mesa Plant

P.0. Box 1128

San Diego, CA 92712

Attn: Dr. Ketchum

The Aerospace Corporation

Space Sciences Lab.

P.0. Box 92957

Los Angeles, California 90009

Attn: Dr. Y. T. Chiu

The Takagi Research Laboratory

Department of Electronics

Kyoto University

Yoshidahonmachi Sakyo-ku Kyoto 606

JAPAN

Attn: Dr. Toshinori Takagi

Department of Aeronautics

Faculty of Engineering

University of Tokyo

7-3-1, Hongo, Bunkyo-ku

Tokyo, JAPAN

Attn: Prof. Itsuro Kimura

Prof. Tom Maul

P.0. Box 98182

Tsim Sha Tsui Post Office

Kowloon, Hong Kong

British Crown Colony

Mr. Susumu Masakj

Department of Electronics

Tokyo National Technical College

No. 1220-2

Kunugida-cha, Hachioji 193

Tokyo, JAPAN

Mr. Curtis Haynes

Tektronix Inc.

M.S. 50-431

P.0. Box 500

Beaverton, Oregon 97077 
Copies

Prof. Paul Wilbur

Mechanical Engineering Department

Colorado State University

Fort Collins, Colorado 80523

Dr. John Barber

International Applied Physics Inc.

7546 McEwen Road

Dayton, Ohio 45459

Dr. Ron Hawke

Lawrence Livermore Laboratory

Livermore, California 94550

Dr. Richard A. Marshall

University of Texas

Taylor Hall 167

Austin, Texas 78712

Prof. Harold R. Kaufnan

Department of Physics

Colorado State University

Fort Collins, Colorado 80523

Dr. V. V. Zhurin

Computing Center of the USSR

Academy of Sciences

Vavilova 40

117333 Moscow, B-333

USSR

Dr. M. Krishnan

Department of Applied Physics

P.0. Box 2159

Yale Station

New Haven, Connecticut 06520

Mr. John Brophy

G.S. $91 p$

Martin Marietta Corp.

P.0. Box 1681

Vandenburg AFB, CA 93437

Lt. Phil Roberts

AFRPL/LKDH, M.S. 24

Edwards Air Force Base, CA 93523 


\section{End of Document}

